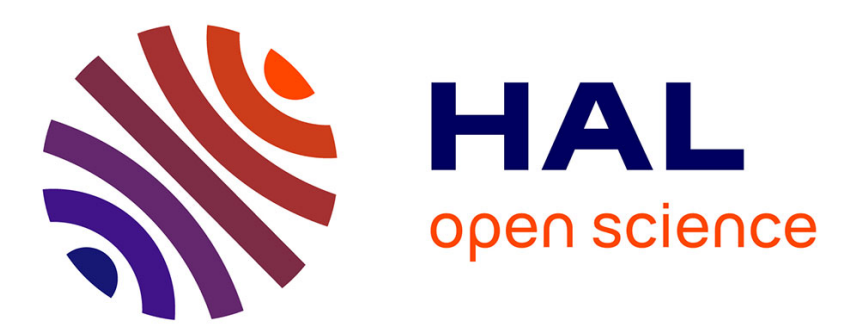

\title{
Two-phase flow in inclined tubes with specific reference to condensation: A review
}

\author{
Stéphane Lips, Josua P. Meyer
}

\section{To cite this version:}

Stéphane Lips, Josua P. Meyer. Two-phase flow in inclined tubes with specific reference to condensation: A review. International Journal of Multiphase Flow, 2011, 37, pp.845-859. 10.1016/j.ijmultiphaseflow.2011.04.005 . hal-01470346

\section{HAL Id: hal-01470346 https://hal.science/hal-01470346}

Submitted on 20 Mar 2019

HAL is a multi-disciplinary open access archive for the deposit and dissemination of scientific research documents, whether they are published or not. The documents may come from teaching and research institutions in France or abroad, or from public or private research centers.
L'archive ouverte pluridisciplinaire HAL, est destinée au dépôt et à la diffusion de documents scientifiques de niveau recherche, publiés ou non, émanant des établissements d'enseignement et de recherche français ou étrangers, des laboratoires publics ou privés. 


\section{Two-phase flow in inclined tubes with specific reference to condensation: a}

\section{review}

Stéphane Lips, Josua P. Meyer*

Department of Mechanical and Aeronautical Engineering, University of Pretoria, Pretoria, 0002, South Africa

Keywords:

Condensation

Void fraction

Pressure drop

Flow pattern

Heat transfer coefficient

\section{ABSTRACT}

Tilting influences the flow patterns and thus the heat transfer and pressure drop during condensation in smooth tubes. However, few studies are available on diabatic two-phase flows in inclined tubes. The purpose of the present paper is to review two-phase flow in inclined tubes, with specific reference to condensation. Firstly, the paper reviews convective condensation in horizontal tubes. Secondly, an overview is given of two-phase flow in inclined tubes. Thirdly, a review is conducted on condensation in inclined tubes. It is shown for convective condensation in inclined tubes that the inclination angle influences the heat transfer coefficient. The heat transfer coefficient can be increased or decreased depending on the experimental conditions, and especially the flow pattern. Under certain conditions, an inclination angle may exist, which leads to an optimum heat transfer coefficient. Furthermore, this paper highlights the lack of experimental studies for the prediction of the trends of the inclination angle in two-phase flows during phase change.

\footnotetext{
* Corresponding author. Tel.: +27 (0)12 420 3104; Fax: +27 (0)12 3625124

E-mail address: josua.meyer@up.ac.za
} 


\section{Introduction}

In-tube condensation of refrigerants in water- and air-cooled condensers is extensively used in the air-conditioning, refrigeration, automotive and process industries. Thus, a good understanding of such diabatic two-phase flows is required to optimally design these systems, increase their energy efficiency and save space and material. The use of more environmentally friendly refrigerants has further emphasised this need. In the last few years, several research teams have conducted studies of convective condensation in horizontal tubes. In these studies, flow pattern maps and correlations have been developed to accurately predict two-phase heat transfer and pressure drops in horizontal two-phase heat exchangers.

Few studies on diabatic two-phase flows in inclined tubes have been published in the literature. Tilting the tubes influence the flow pattern maps and thus the heat transfer and pressure drop. Depending on the angle of inclination and the mass flux in the tube, heat transfer can be increased or decreased. A better understanding of the effect of the tube inclination on the thermal and hydrodynamic flow properties is also required to improve heat exchangers in process industries or to optimise heat transfer in compact applications, where heat exchangers cannot be horizontally oriented.

These considerations motivate the present literature review of two-phase flows in order to better understand the phenomena that occur during condensation in inclined tubes. The purpose of the first part of this literature survey is to focus on convective condensation in horizontal tubes, which has been widely studied by different international research teams during the last few years.

The second part is dedicated to an overview of two-phase flows in inclined tubes. Most of the studies have been performed by using water and air, whose properties differ from refrigerants, but they will help to understand the influence of gravitational and inclination effects on two-phase flows.

The purpose of the third part is to focus on condensation in inclined tubes. The studies can be classified into two categories: on the one hand, the studies where the flow is mainly driven by gravitational effect (i.e. thermosyphons) and on the other hand, the studies where the flow is mainly driven by an external mechanical force (forced convection).

\section{Condensation in horizontal smooth tubes}

The condensation process in horizontal tubes has been the object of many articles in the past. Several review articles give a good overview of the state of the art in this field. Cavallini et al. (2003) proposed a review about condensation inside and outside smooth and enhanced tubes. Liebenberg and Meyer (2008) published a review of flow pattern-based predictive correlations for condensation in smooth and enhanced tubes. Miyara (2008) undertook a review of condensation of hydrocarbons. Recently, Dalkilic and Wongwises (2009) have published an "intensive literature review of condensation inside smooth and enhanced tubes". 
To summarise, the accepted model to predict flow pattern maps and heat transfer coefficients during convective condensation of refrigerant in tubes seems to be the Thome and El Hajal model (Thome, 2006). In essence, the heat transfer coefficient correlations are based on a flow pattern map developed for condensation in horizontal tubes (El Hajal et al., 2003; Thome et al., 2003). This flow pattern map was built from that of Kattan et al. (1998), which was an extension of that of Steiner (1993) and that of Taitel and Dukler (1976). The map and the heat transfer correlation were slightly improved by Suliman et al. (2009) for the low mass flux range.

If the existing flow pattern maps and heat transfer correlations developed for condensation in horizontal smooth tubes can be considered as satisfactory, then more research needs to be done on the determination of the pressure drops. Most of the correlations for pressure drop in two-phase flows have been developed for adiabatic flows or for evaporation. Furthermore, the heat flux is never taken into account in the correlations. The accuracy of the different correlations available in the literature also depends on the flow pattern. For example, Ould Didi et al. (2002) compared their experimental pressure drop results obtained during convective evaporation in smooth horizontal tubes with different correlations. They found that the method of Müller-Steinhagen and Heck (1986) was the best for annular flows while the method of Grönnerud (1972) gave the best predictions for both intermittent and stratified-wavy flows. As a consequence, there is a need for a general mechanistic model. To fill this gap, Moreno Quibén and Thome (2007a and 2007b) recently published a flow pattern-based two-phase frictional pressure drop model for horizontal tubes. However, this model was developed for convective evaporation and so far, no comparison of this model has been made with experimental data obtained with condensation of refrigerants.

In the case of convective evaporation, the pressure drop was found to increase almost linearly with the vapour quality up to a peak after which it decreased abruptly. Later, Revellin and Haberschill (2009) showed that it was possible to simplify the model of Moreno Quibén and Thome by considering only the pressure drop for fully liquid and fully vapour flow, and the properties of the peak of the pressure drop (i.e. the vapour quality and the pressure drop). The pressure drop between these three points could then be calculated with a linear interpolation between the points.

It can be questioned if this kind of model can be applied for convective condensation as well. Moreno Quibén and Thome (2007a) compared pressure drops during evaporation and adiabatic flows. They concluded that the heat flux influenced the pressure drop only for high vapour quality, after the peak, but this result cannot be extrapolated to condensing flows. It has been shown that suction or blowing could affect the momentum transfer and thus affecting the pressure drops in a flow and a correction factor can be applied (Mickley et al., 1953). For condensation, this correction factor is only significant for high mass fluxes and leads to an increase of the pressure drop when the heat flux increases (Cavallini et al., 2000; 2001). However, this result contradicts the experimentation of Yan and Lin (1999), who conducted an experimental study of pressure drops during the condensation of R134a in a $2 \mathrm{~mm}$ internal diameter tube. They found that the pressure drop decreased when the heat flux increased 
for the whole range of vapour qualities. Also, the authors proposed a correlation that does not take into account the heat flux.

As a conclusion, on the one hand, some widely accepted predictive tools have been developed for condensation in horizontal tubes in terms of flow patterns and heat transfer coefficients. However, more studies should be conducted on the effect of the heat flux on the flow properties, especially for very low and very high heat fluxes. The range of validity of the models in terms of heat flux is never specified. On the other hand, the condensing effect on the pressure drop is not clear as several studies contradict each other. There is a need for accurate pressure drop correlations and it would be interesting to adapt the model of Moreno Quibén and Thome (2007a and 2007b) to condensing flows. For this purpose, accurate experimental pressure drop studies during convective condensation should be conducted.

\section{Two-phase flow in inclined smooth tubes}

A review of the most important experimental and theoretical studies of two-phase flows in inclined tubes is presented in this section. It is not the purpose to be an exhaustive literature review of two-phase flow in inclined tubes: its goal is to highlight the characteristics of such flows and to understand the effect of the gravitational forces on their properties. The different kinds of flow pattern maps presented in the literature are described, as well as the correlations for the void fractions heat transfer coefficients and pressure drops, which take into account the tube inclination angle.

\subsection{Flow pattern maps}

The first step to understand and to predict the properties of two-phase flow is to determine the type of flow, i.e. the flow pattern. Each flow pattern is led by different physical phenomena (e.g. gravity for stratified flow, shear for annular flow) and thus, the different models and correlations given in the literature often apply only to a specific flow pattern. The determination of the configuration of the flow depending on the flow conditions can be done thanks to flow pattern maps. Cheng et al. (2008) have recently conducted a review of articles dealing with two-phase flow patterns and flow pattern maps. They provided a summary of experimental and theoretical studies on flow patterns in macro- and microscale smooth channels. Many flow pattern maps have been developed for gas-liquid flow in horizontal and vertical tubes, but there are comparatively few studies that deal with the whole range of tube inclinations. For horizontal tubes, the most accepted flow pattern map is probably that of Mandhane et al. (1974). For vertical tubes with upward flow, the most-used flow pattern maps are those of Hewitt and Roberts (1969) and of Fair (1960). All of them were developed for air-water flows.

Taitel and Dukler (1976) developed a flow pattern map for horizontal and near horizontal flows. This map is limited to low inclination angles (typically less than $5^{\circ}$ ) and is valid for gas liquid flow only. 
However, the flow pattern map of Taitel and Dukler is the base for many other studies that tried to improve it and to extend the conditions for which it is possible to use the map.

Several studies on flow patterns deal only with two-phase flow in slightly inclined tubes. However, the range of the experimental conditions tested is very limited. For example, Grolman and Fortuin (1997b) used a stratified model to predict the stratified-intermittent and stratified-annular flow pattern transitions in slightly inclined tubes ( $3^{\circ}$ downward to $6^{\circ}$ upward flow). They compared the prediction of their model with experiments performed with air-water and air-tetradecane flows for three different tube diameters (15, 26 and $51 \mathrm{~mm})$. More recently, Ghajar and Kim (2005) studied experimentally the influence of the inclination angle on the flow pattern for slightly upward air-water flow in a $27.9 \mathrm{~mm}$ diameter tube. They observed an inclination effect on the slug-plug and slug-bubbly transitions, but the annular-bubbly transition looked to be insensitive to the inclination angle for such a small inclination angle, i.e. lower than $7^{\circ}$ (Fig. 11).

Brauner and Moalem Maron (1992) focused on the stratified-non-stratified transition in slightly inclined tubes $\left( \pm 10^{\circ}\right)$. In practice, the transition between stratified and non-stratified flow patterns does not occur suddenly, but can be described as a continuously increasing disturbance of the stratified-wavy flow pattern. Hence, Brauner and Moalem Maron determined a "buffer zone", delimited by a lower and an upper bound determined by stability analyses. Among others, they studied the influence of the inclination angle and concluded that a downward inclination increased the thickness of the buffer zone. The notion of a buffer zone highlights the difficulty to define accurately the different flow patterns that can be encountered, which is a major recurrent issue in flow pattern studies.

For the whole range of tube inclinations, the most-used flow pattern map is the one of Barnea (1987), which predicts the flow pattern flow for upward and downward flow from horizontal to vertical orientations. Later, Zhang et al. (2003) estimated that the model of Barnea for transition from slug to dispersed bubble flow shows an incorrect trend for high gas flow rates. Thus, they proposed a new model for this transition, based on a balance between the kinetic energy of the liquid and the surface energy of dispersed gas bubbles. This model also enables the prediction of the liquid hold-up in slug flows. The comparison with experimental data obtained with air-water flow for the whole range of inclination angles (from vertical downward to vertical upward) shows a good agreement of the model with experiments.

Weisman et al. (1979) proposed a flow pattern map for two-phase flows in smooth horizontal tubes. In a following article, they extended their flow pattern map for the whole range of inclination angles for upward flows (Weisman and Kang, 1981). For slightly upward flows, they found that the only difference with horizontal flow was the disappearance of the stratified flow. For sharply inclined tubes, they proposed new transitions that take into account the inclination angle of the tube. Their flow pattern map was based on experimental data obtained with air-water and R113 flowing in a $25 \mathrm{~mm}$ tube. Crawford et al. (1985) presented experimental flow patterns for downward flows of R113 in a $25 \mathrm{~mm}$ inclined tube. The angle of inclination varied from $15^{\circ}$ to $90^{\circ}$. They proposed an overall flow pattern 
map for downward flow based on the flow pattern map of Weisman et al. (1979) and of Weisman and Kang (1981).

The flow pattern maps of Barnea (1987) and Crawford et al. (1985) are the only two that deal with the whole range of inclination angle. However, very few comparisons with experimental data were conducted after the publication of the models and it is difficult to determine their validity for experimental conditions which differ from the ones that the authors used in their original papers. For example, Spedding et al. (1998) presented experimental data on horizontal and slightly inclined flows $\left(+5^{\circ}, 0^{\circ}\right.$ and $\left.-5^{\circ}\right)$ for a $58 \mathrm{~mm}$ inner diameter tube with an air-water system flowing in a co-current direction. They compared their results with existing flow pattern maps (Taitel and Dukler, 1976) and Mukherjee and Brill (1985a) for a horizontal orientation and Spedding and Nguyen (1980) for inclined orientations). They concluded that all flow regime maps failed to correctly predict their data. In general, it seems as if most of the flow patterns maps seem to be valid only for the conditions they have been developed in.

In order to improve the accuracy of two-phase flow models, a better understanding of the flow is necessary. Spindler and Hahne (1999) studied the radial distribution of local void fraction and bubble frequency in upward inclined air-water flow. The angle of inclination has a strong effect on these parameters and the authors demonstrated that the flow pattern transition changes the equivalent bubble diameter. Lioumbas et al. (2005) conducted an intensive experimental study of stratified air-water downward flow and they particularly focused on the transition between smooth and wavy-stratified flow. They used a high-speed camera for the wave characterisation, a parallel wire conductance probe to determine the liquid layer thickness as a function of time and a laser doppler anemometer to measure the local axial velocity in the liquid film. This experimental set-up allowed the authors to completely characterise the flow and to study the effect of the interfacial shear stress on the flow properties. In another article, Lioumbas et al. (2007) also studied air-glycerin and air-surfactant (Tween®) flows instead of an air-water flow in order to determine the effect of the liquid properties on the formations of the interfacial waves. This kind of study highlights the necessity of developing elaborated test sections in order to improve the understanding of the flow so that the accuracy of mechanistic flow models can be improved.

This limited review of flow patterns for inclined flows shows that most of the studies were conducted with air-water flow in tubes with diameters of approximately $25 \mathrm{~mm}$. The inclination angle has been shown to have a strong effect on the flow pattern, even for very low angles. So far, a model validation for the whole range of inclination angles, for different kinds of fluids and for different tube diameters does not exist. Thus, further studies are necessary to develop a robust predictive tool to predict the two-phase flow patterns in inclined tubes. 


\subsection{Void fraction correlations}

The properties of a two-phase flow are strongly dependent on flow patterns, and on the ratio between the liquid and the vapour cross-sectional area. The void fraction is thus an important parameter of the flow. However, modelling the evolution of the void fraction with the vapour quality is a major issue in the study of two-phase flows. Void fraction models can be classified into four categories:

- Slip ratio correlation: $\varepsilon=\left[1+S\left(\frac{1-x}{x}\right)\left(\frac{\rho_{g}}{\rho_{l}}\right)\left(\frac{\mu_{l}}{\mu_{g}}\right)\right]^{-1}$,

- Correlations relative to the homogeneous model: $\varepsilon=K \varepsilon_{h}$,

- Drift flux correlations

- Empirical correlations

where $\varepsilon, S, x, \rho$ and $\mu$ denote respectively the void fraction, the slip ratio, the vapour quality, the density and the dynamic viscosity. The subscripts $l$ and $g$ refer to the liquid and gas phase respectively. $K$ is a non-dimensional parameter and $\varepsilon_{\mathrm{h}}$ is the void fraction predicted by the homogeneous model $(S=1)$.

These correlations have been developed for horizontal or vertical flow inside tubes, or for twophase flow between rod bundles. Different articles attempt to summarise the state of the art about void fractions. Spedding (1997) conducted a review about void fraction correlations for upward and downward two-phase flows. He concluded that no model succeeds in predicting the void fraction for the stratified flow regime. For downward flow, he highlighted the need to develop models for low mass fluxes. For high mass fluxes, the gravitational forces become negligible and some models developed for horizontal or vertical flows can be used successfully.

Several authors (Diener and Friedel, 1998; Spedding et al., 1998; Woldesemayat and Ghajar, 2007) compared their experimental results with the prediction of numerous models presented in the literature for horizontal, inclined and vertical upward flows, including a large range of mass fluxes and fluids. However, only a few of the available correlations account for the inclination angle.

Beggs and Brill (1973) proposed a correlation to predict the void fraction for all inclination angles (both downward and upward flow). Data were collected for air-water flow in $25 \mathrm{~mm}$ and $38 \mathrm{~mm}$ diameter tubes. The correlation can be written as:

$$
1-\varepsilon=\left(1-\varepsilon_{0}\right)\left[1+C\left(\sin 1.8 \beta-\frac{1}{3} \sin ^{3} 1.8 \beta\right)\right]
$$

where $\beta$ is the inclination angle of the tube ( $\beta<0$ for downward flow and $\beta>0$ for upward flow), $\varepsilon_{0}$ is the void fraction for horizontal orientation and $C$ is a function of the flow pattern, the orientation of the pipe (uphill flow or downhill flow), the liquid velocity number $U_{s l}\left(\rho_{l} / g \sigma\right)^{0.25}$, and the Froude mixture number $U_{m}{ }^{2} / g D . U_{s l}$ and $U_{s g}$ are the liquid and gas superficial velocities respectively and $U_{\mathrm{m}}$ is the mixture velocity $\left(U_{m}=U_{s l}+U_{s g}\right) . g, \sigma$ and $D$ denote the gravitational acceleration, the surface tension of the fluid and the tube diameter respectively.

This correlation leads to a maximum and a minimum void fraction for an angle of $50^{\circ}$ downward and upward respectively. The effect of the inclination angle on the void fraction is shown in Fig. 12 for 
different flow conditions. $C_{l}$ is the input liquid volume fraction: $C_{l}=U_{s l} /\left(U_{s l}+U_{s g}\right)$. It is interesting to note that the void fraction for horizontal, vertical upward and vertical downward flow is very close. This can explain why correlations developed for vertical flow can also be used for horizontal orientations.

Five other correlations are available in the literature to predict void fractions in inclined tubes. However, they are not in a good agreement to each other:

- Greskovich and Cooper (1975) developed a correlation for upward air-water flow where the homogeneous void fraction is corrected by a term accounting for the inclination angle and the Froude number. They found that the void fraction decreases when the inclination angle increases.

- Nguyen and Spedding (1977) published an intensive experimental study about void fraction in inclined air-water flow in a $5.5 \mathrm{~mm}$ inner diameter tube. They identified three types of hold-up regimes depending on the phase superficial velocities. For two of them, they expressed the void fraction using a drift flux correlation of the type:

$$
\varepsilon=\frac{U_{s g}}{C^{*} U_{m}+B}
$$

where $B$ and $C^{*}$ are the initial function and the two-phase field distribution coefficient respectively. For the two different hold-up regimes, the authors proposed some graphs to determine $C^{*}$ and $B / \sqrt{g D}$ as a function of the inclination angle and the term $\frac{\mu_{l}}{\rho_{l} g D^{3}}\left(\frac{Q_{l}}{\pi D}\right)$, where $Q_{l}$ is the liquid volumetric flow rate. For the third hold-up regime, which occurs for high mixture velocities, they proposed a correlation only for horizontal flow.

- Mukherjee and Brill (1983) developed three different relations for upward flows and for stratified and non-stratified downward flows. The void fraction depended on the liquid and gas superficial velocities and on the inclination angle. This correlation leads to a minimum void fraction for an angle of $32.8^{\circ}$ (upward flow) and a maximum one for an angle of $-35.2^{\circ}$ or $-45.7^{\circ}$ for downward flow, depending on whether the flow is stratified or not.

- Gomez et al. (2000) developed their correlation for upward flows with different fluid combinations (including air, kerosene, oil, water and Freon) with pipe diameters ranging from $5.1 \mathrm{~cm}$ to $20.3 \mathrm{~cm}$. In their correlation, the void fraction depended only on the inclination angle and on the liquid-only Reynolds number. The void fraction increases continuously when the angle of inclination increases.

- Woldesemayat and Ghajar (2007) showed that none of these correlations corresponds well with the void fractions of their experimental database, which consisted of 2845 data points obtained for horizontal and upward flows with air-water, air-kerosene and natural gas-water mixtures. The tube diameters ranged from 12.7 to $102.26 \mathrm{~mm}$. They found that the database is best described by the correlations of Toshiba (Coddington and Macian, 2002), Rouhani and Axelsson (1970) and Dix (Coddington and Macian, 2002). However, none of these takes into account the effect of the inclination angle. Thus, Woldesemayat and Ghajar proposed an improvement of the Dix correlation for void 
fraction by adding a term taking into account the inclination angle. The correlation is based on the drift flux model and is valid only for upward flows and predicts $85.6 \%$ of the experimental data within $\pm 15 \%$ and $60.4 \%$ within $\pm 5 \%$. The correlation is written as:

$$
\left.=\frac{U_{s g}}{U_{s g}\left(1+\left(\frac{U_{s l}}{U_{s g}}\right)^{\left(\rho_{g} / \rho_{l}\right)^{0.1}}\right)+2.9\left(\frac{g D \sigma(1+\cos \beta)\left(\rho_{l}-\rho_{v}\right)}{\rho_{l}^{2}}\right)^{0.25}(1.22(1+\sin \beta))^{P_{a t m} / P_{\text {syst }}}}\right)
$$

where $P_{\text {atm }}$ is the atmospheric pressure and $P_{\text {sys }}$ is the pressure in the system. For a system at atmospheric pressure, this correlation leads to a minimal void fraction for an inclination angle of $70^{\circ}$. The value of the inclination angle that leads to the minimum void fraction decreases when the pressure in the system increases (for example, its value is $45^{\circ}$ for $P_{s y s}=4 \mathrm{~atm}$ ).

To conclude, it seems that there is no agreement between the different correlations proposed in the literature: some authors observed a minimum in the void fraction during upward flows and a maximum during downward flows. The discrepancy between the models can be explained by the fact that the local minima or maxima depend on the result of a balance between different physical phenomena. The difference in the fluids and in the experimental conditions is probably the cause of the difference between the conclusions of the authors. More experimental studies are required to get a good overview of and to highlight the general trends of the void fraction as a function of the inclination angle for different experimental conditions and using different types of fluids.

\subsection{Modelling of separated flows}

Another approach to determine the flow properties is to attempt to develop mechanistic models of two-phase flows. The separated flows, namely stratified, stratified-wavy and annular flows, have been the object of numerous theoretical studies in order to develop models permitting the prediction of the liquid hold-up and the properties of the flow for horizontal and inclined pipes (liquid film thickness, pressure drop, heat transfer coefficient). Stratified flow, together with its transition to annular flow, is certainly the flow most affected by the inclination angle of the tube, as it occurs for low mass fluxes and thus for mass fluxes where gravity forces cannot be neglected compared with shear forces.

The flow pattern of Taitel and Dukler (1976) is based on a model of stratified flow where the liquid-vapour interface is supposed to be flat (Fig. 13). In steady-state separated flow, the following two momentum equations are satisfied:

$$
\begin{gathered}
A_{g}\left(-\frac{d P}{d L}\right)_{g}=\tau_{g w} S_{g}+\tau_{i} S_{i}+A_{g} \rho_{g} g \sin \beta \\
A_{l}\left(-\frac{d P}{d L}\right)_{l}=\tau_{l w} S_{l}-\tau_{i} S_{i}+A_{l} \rho_{l} g \sin \beta
\end{gathered}
$$

where $A, L, S$ and $\tau$ denote the cross-sectional area, the tube length, the interface length and the shear stress respectively. The subscripts $w$ and $i$ refer to the wall and the liquid-vapour interface respectively. 
The model is based on the force balance between the pressure drop in the liquid and in the vapour phase. The equation to solve becomes:

$$
\tau_{l w} \frac{S_{l}}{A_{l}}-\tau_{g w} \frac{S_{g}}{A_{g}}-\tau_{i} S_{i}\left(\frac{1}{A_{l}}+\frac{1}{A_{g}}\right)+\left(\rho_{l}-\rho_{g}\right) g \sin \beta=0
$$

From this equation can be solved the velocities of each phase, the liquid hold-up and the pressure drop in the flow.

Several other models have been developed in order to try to improve the Taitel and Dukler model. The changes are mainly in the calculation of the shear stresses and in the calculation of the interfacial perimeters. Spedding et al. (1998) compared the results of some of these models with their experimental database of air-water flow in slightly inclined tubes.

Some models have also been developed for specific kinds of flows: for example, Xu et al. (2007) studied numerically and experimentally a two-phase co-current flow in inclined tubes with air and a non-Newtonian fluid. More recently, Ullmann et al. (2003) have conducted a theoretical and experimental study about the existence of multihold-ups in co-current stratified flow in inclined tubes. They showed that theoretical models can predict several hold-ups for counter-current (maximum two hold-ups) and co-current flows (maximum three hold-ups) in inclined tubes. They also found the existence of multihold-ups experimentally. This phenomenon is associated with hysteresis effects and thus needs to be taken into account in the prediction of the flow properties.

Grolman and Fortuin (1997a) developed a semi-empirical model to predict the flow properties in a slightly inclined channel: the modified apparent rough surface (MARS) model. This model is based on the model of Hart et al. (1989), developed for horizontal flows only. Empirical relations are used to calculate the wetted perimeter and the friction factor. An equivalent relative roughness is taken into account in order to calculate the interfacial friction factor. The comparison of the model with an experimental database obtained with air-water and tetradecane-air flows showed a good agreement between measurements and numerical results. The authors also showed that the assumption of considering a smooth interface, as in the model of Taitel and Dukler (instead of considering an equivalent relative roughness as in the MARS model) leads to an unacceptable error for upward flows.

However, the assumption of a flat liquid-vapour interface is not always verified experimentally and some efforts have been made to predict more accurately the shape of the interface. The curvature interface and the wetted perimeter of the tube increase gradually with increasing gas and liquid flow rates. Fukano and Ousaka (1989) explained the increase of the curvature by three phenomena: a) for high vapour velocity, secondary flow in the gas can lead to circumferential shear forces at the interface; b) a mass transfer occurs from the bottom to the top of the tube by entrainment and deposition of liquid droplets by the vapour; c) the waves present in the flow spread the liquid film on the wall through a pumping action due to their shape and the capillary forces (Fig. 14).

Laurinat et al. (1985) developed a model to predict this phenomenon. They found that the secondary gas flow was the most important factor to transfer liquid towards the top of the tube against 
gravity. Fukano and Ousaka (1989) improved the model of Laurinat et al., for the prediction of the circumferential liquid film thickness for annular and stratified flows. They found that the liquid film is transferred in the circumferential direction mainly by the pumping action of the disturbance waves. Brauner et al. (1996) proposed a different way of predicting the curvature of the interface by assuming that the interface configuration corresponds to the minimum of the total system energy. In their study, they considered only the potential and the surface energy. They showed that the liquid-wall contact angle is an important parameter for the determination of the interface shape. In a following article (Brauner et al., 1998), they proposed a model to determine the properties of a two-phase stratified flow in inclined tubes. Later, Wang and $\mathrm{Du}$ (2000) used the principle of the minimisation of the total energy of the flow in order to study the effect of the inclination angle on the interface shape during laminar condensation of steam inside an inclined tube. However, contrary to Brauner et al., they took into consideration not only the potential and surface energies, but also the kinetic energy of the fluids.

Experimental results, and especially film thickness measurements, are necessary to test the validity of the different models of separated flows with curved interfaces. However, few data are available in the literature for inclined flow. Fukano and Ousaka (1989) published experimental results for annular and open annular air-water flow in a $25 \mathrm{~mm}$ inside diameter tube. They measured the liquid film distribution in the tube for liquid superficial velocities between 0.006 and $0.1 \mathrm{~m} / \mathrm{s}$ and for two vapour superficial velocities of 30 and $50 \mathrm{~m} / \mathrm{s}$. The inclination angle ranged from $10^{\circ}$ downward flow to $15^{\circ}$ upward flow. Their results were very close to those of Hetsroni et al. (2003), which presented some liquid film thickness measurements obtained with a conductive tomography for air-water flow in a $25 \mathrm{~mm}$ inside diameter inclined tube of $8^{\circ}$ upward flow. Liquid and vapour superficial velocities ranged from 0.016 to $0.099 \mathrm{~m} / \mathrm{s}$ and from 24 to $42 \mathrm{~m} / \mathrm{s}$ respectively. In these conditions, the maximum liquid film thickness measured was about $0.6 \mathrm{~mm}$ for low gas mass fluxes and high liquid mass fluxes. More recently, Geraci et al. (2007a) have performed experiments with a tube diameter of $38 \mathrm{~mm}$ for upward air-water flow (from $0^{\circ}$ to $85^{\circ}$ ). They measured the local film thickness using flush-mounted and parallel wire conductance probes. They tested two superficial liquid velocities $(0.007 \mathrm{~m} / \mathrm{s}$ and 0.079 $\mathrm{m} / \mathrm{s})$ and two superficial vapour velocities ( $15 \mathrm{~m} / \mathrm{s}$ and $21.5 \mathrm{~m} / \mathrm{s})$.

By comparing the different experimental results, we noticed a big discrepancy between the work of Hetsroni et al. (2003), Geraci et al. (2007a) and Fukano and Ousaka (1989). In almost the same superficial velocity conditions, the liquid thickness measured by Geraci et al. in a $38 \mathrm{~mm}$ inside diameter tube is about 10 times bigger than that measured by Hetsroni et al. or by Fukano and Ousaka in a $25 \mathrm{~mm}$ inside diameter tube. The difference in tube diameter can hardly explain the difference in the result. Geraci et al. also showed that the model of Foukano and Ousaka systematically underpredicted the liquid film thickness compared with their measurements. It must mean that the experimental conditions were not similar in the two studies but the lack of more experimental data for the liquid film thickness distribution cannot explain the phenomena. Thus, more experimental studies are required to get a bigger 
experimental database of liquid film thickness during two-phase flow in inclined tubes in order to be able to validate the different models presented in the literature.

Moreover, all these experimental results have been obtained with air as the gas phase. The liquid-vapour interface has been found to have a high curvature and the assumption of a flat interface seems never to be verified in practice for the considered range of tube diameter and fluid flow rates. However, Ursenbacher et al. (2004) performed the visualisation of the interface shape during the evaporation of R22 and R410a in a horizontal smooth tube with a $13.6 \mathrm{~mm}$ inner tube diameter. They measured the dry perimeter of the tube with an optical measurement technique and found that the liquidvapour interface can be found to be nearly flat in some experimental conditions. This can be explained by the evaporation process that will tend to minimise the curvature of the interface because evaporation occurs mainly where the liquid film is the thinnest. This specific example shows that air-water flows and liquid-vapour refrigerant flows can have two totally different behaviours if evaporation or condensation occurs. Thus, more studies are necessary to adapt separated two-component flow models to one-component saturated diabatic two-phase flows.

Note that if the greater part of the studies deal with separated flows, some authors also try to model the other flow regimes. For example, Kokal and Stanislav (1989b) and later, Abdul-Majeed and Al-Mashat (2000) developed a mechanistic model for inclined two-phase slug flows. It seems as if the model of Abdul-Majeed and Al-Mashat describes the experimental data of several studies well in terms of void fraction and pressure drop.

In conclusion, we can say that specific mechanistic models need to be developed for each flow pattern. Specific experimental set-ups are necessary to validate each model in various conditions in order to check the validity of the assumptions of the models. So far, it seems as if no model is widely accepted by different researchers for the modelling of two-phase flows in inclined tubes. This constitutes a major challenge in order to increase the global understanding of two-phase flows in inclined tubes.

\subsection{Entrainment}

A limitation of the existing modelling of two-phase flows and of void fraction correlations is the difficulty of taking into account the liquid entrainment in the two-phase flow. For high gas flow rates, the interfacial shear stresses become so important that a part of the liquid is entrained by the vapour core as small liquid droplets. This phenomenon has a great effect on the flow properties. Numerous experimental and theoretical studies have been performed to try to develop correlations for horizontal flow (Pan and Hanratty, 2002a) and for vertical flows (Pan and Hanratty, 2002b; Sawant et al., 2008).

For flows at an inclination angle, Geraci et al. (2007b) provided liquid entrainment measurements as function of the vapour superficial velocity and inclination angle. They found that the entrained fraction was between $7 \%$ and $30 \%$ and that it did not depend on the inclination angle. However, Magrini et al. (2010) observed an inclination effect on entrainment fraction. 
Note that all these studies have been performed with air-water flows. The entrainment is strongly dependent on the surface energy and thus on the liquid-gas surface tension. More experiments are necessary to study the effect of inclination on the entrainment for other fluids with a lower surface tension.

\section{5. $\quad$ Pressure drop}

Many pressure drop correlations can be found in the literature for two-phase flow inside horizontal tubes, but comparatively few studies have been conducted in order to determine the effect of the inclination angle on the pressure drop. The actual total pressure drop $\left(\Delta P_{t o t}\right)$ is the sum of three different terms: the static pressure drop $\left(\Delta P_{\text {static }}\right)$, the momentum pressure drop $\left(\Delta P_{\text {mom }}\right)$ and the frictional pressure drop $\left(\Delta P_{\text {fric }}\right)$ :

$$
\Delta P_{\text {tot }}=\Delta P_{\text {static }}+\Delta P_{\text {mom }}+\Delta P_{\text {fric }}
$$

The static pressure drop is directly linked to the inclination angle $(\beta)$ of the tube. If we consider a homogeneous model, it can be expressed as:

$$
\Delta P_{\text {static }}=\rho_{h} g L \sin \beta
$$

where the homogeneous density $\rho_{h}$ of the fluid is:

$$
\rho_{h}=\rho_{l}(1-\varepsilon)+\rho_{v} \varepsilon
$$

However, for stratified flows, the static pressure drop is determined considering the density of the gas (Mukherjee and Brill, 1985b):

$$
\Delta P_{\text {static }}=\rho_{g} g L \sin \beta
$$

Thus, the void fraction is an important parameter in the determination of the effect of the inclination angle on the pressure drop in two-phase flow, as shown by Dalkilic et al. (2008).

The momentum pressure drop depends on the kinetic energy at the inlet and the outlet of the tube and thus on the change of the void fraction with the vapour quality, which depends on the inclination angle:

$$
\Delta P_{\text {mom }}=G^{2}\left[\left(\frac{(1-x)^{2}}{\rho_{l}(1-\varepsilon)}+\frac{x^{2}}{\rho_{g} \varepsilon}\right)_{o u t}-\left(\frac{(1-x)^{2}}{\rho_{l}(1-\varepsilon)}+\frac{x^{2}}{\rho_{g} \varepsilon}\right)_{\text {in }}\right]
$$

where $G$ is the mass flux. The subscripts in and out refer to the inlet and outlet of the tube respectively.

Lastly, the frictional pressure drop depends on the flow pattern and thus can also depend on the inclination angle of the pipe.

For vertical tubes, the most-used correlation for two-phase frictional pressure drop is the correlation of Friedel (1979), which is based on the concept of the two-phase flow multiplier $\Phi_{l 0}$ :

$$
\left(-\frac{\partial P}{\partial z}\right)_{\text {fric }}=\Phi_{l 0}^{2}\left(-\frac{\partial P}{\partial z}\right)_{\text {fric }, l 0}
$$


where $\left(-\frac{\partial P}{\partial z}\right)_{f r i c, l 0}=f_{l 0} 4 \frac{1}{D_{h}} \frac{G^{2}}{2 \rho_{l}}$ with $f_{l 0}=0.079\left(\frac{G D_{h}}{\mu_{l}}\right)^{-0.25} \cdot f$ and $D_{h}$ are the friction factor and the hydraulic diameter respectively. $z$ is the coordinate in the direction of the flow and the subscript $l 0$ refers to a fully liquid flow, with quality, $x=0$.

For vertical upward flows, the two-phase multiplier is the same as for horizontal flows:

$$
\Phi_{l 0}^{2}=C+3.21 x^{0.78}(1-x)^{0.224}\left(\frac{\rho_{l}}{\rho_{g}}\right)^{0.91}\left(\frac{\mu_{g}}{\mu_{l}}\right)^{0.19}\left(1-\frac{\mu_{g}}{\mu_{l}}\right)^{0.7} F^{-0.0454} W e^{-0.035}
$$

For vertical downward flow, Friedel's correlation becomes:

$$
\Phi_{l 0}^{2}=C+48.6 x^{0.8}(1-x)^{0.29}\left(\frac{\rho_{l}}{\rho_{g}}\right)^{0.90}\left(\frac{\mu_{g}}{\mu_{l}}\right)^{0.73}\left(1-\frac{\mu_{g}}{\mu_{l}}\right)^{7.4} F r^{0.03} W e^{-0.12}
$$

where $C=(1-x)^{2}+x^{2} \frac{\rho_{l} f_{g 0}}{\rho_{v} f_{l 0}}, F r$ is the Froude number $\left(F r=\frac{G^{2}}{g D \rho_{h}^{2}}\right)$ and We is the Weber number $\left(W e=\frac{G^{2} D}{\rho_{h} \sigma}\right) ; \rho_{h}=\left(\frac{x}{\rho_{g}}+\frac{1-x}{\rho_{l}}\right)^{-1}$. The subscript $g o$ refers to a fully gas flow, with quality, $x=1$.

For turbulent flow $\left(\operatorname{Re}_{\mathrm{fo}}>1055\right)$, Friedel recommends:

$$
f_{f 0}=0.25\left[0.86859 \ln \left(\frac{R e_{f 0}}{1.964 \ln \left(R e_{f 0}\right)-3.8215}\right)\right]^{-2}
$$

where $R e$ is the Reynolds number $\left(R e_{f 0}=\frac{G D}{\mu_{f}}\right)$. The subscript $f$ can refer to the liquid or the gas phase. Hewitt (1994) recommends the Friedel correlation for fluids with $\mu_{l} / \mu_{v}<1000$.

For inclined tubes, Beggs and Brill (1973) proposed a correlation to calculate pressure drop as a function of the inclination angle. Spedding et al. (1982) performed an intensive investigation of pressure drops for a co-current air-water flow in a $4.55 \mathrm{~cm}$ diameter tube for a full range of inclination angles. Fig. 15 is an example of the pressure drop as a function of the inclination angle for a liquid superficial velocity of $0.018 \mathrm{~m} / \mathrm{s}$ and for different mixture velocities. There are different optimal inclination angles for liquid and vapour superficial velocities as well as optimal velocities for a specified inclination angle. This highlights the difficulty of predicting the pressure drop because of the dependence on the flow regimes. On the other hand, it justifies the need for powerful predictive tools in order to design systems with inclined tubes.

In an experimental study of the evaporation of $\mathrm{CO}_{2}$ and $\mathrm{CO}_{2}$-propane mixtures in a tube with an inclination angle of $45^{\circ}$ (upward flow), Cho et al. (2010) found that the pressure drop in an inclined tube is higher than that in a horizontal tube and lower than that in a vertical tube. The authors explain this result by the fact that the importance of intermittent-flow pattern increases when the inclination angle increases, leading to higher pressure drops than those for stratified-flow patterns.

Several other authors proposed different models to predict the pressure drops, but the range of validity of these models is very limited in terms of fluids (Mukherjee and Brill, 1985b) and/or in terms of the inclination angle (Grolman and Fortuin, 1997a; 1997b). 
Once more, we can conclude that there is no general predictive tool that has been validated for the whole range of inclination angles and for various fluids. Different models, sometimes hard to implement, have to be used depending on the conditions. Moreover, the limits of validity of these models are often not clear. The inclination effect on both the gravitational and frictional pressure drop is not fully understood yet and further experimental and theoretical work are thus needed.

\subsection{Heat transfer coefficient}

In diabatic conditions, the heat transfer coefficient of the fluids in a tube is a major parameter in the design of industrial applications such as heat exchangers, as it will directly influence the size and the efficiency of the system. The heat transfer coefficient in two-phase flows is strongly dependent on the flow pattern and on the liquid film thickness of the circumference of the tube. Thus, several authors showed that the inclination angle has a strong effect on the heat transfer, even for slightly inclined tubes:

- Hetsroni et al. (2003) conducted an experimental study of air-water flow in an upward tube with an inclination angle of $8^{\circ}$. Two diameters have been used: 25 and $49.2 \mathrm{~mm}$. They studied flow patterns with a high-speed camera and measured heat transfer coefficients for different liquid and vapour superficial velocities. For annular and stratified flows, they measured the film thickness distribution around the circumference of the tube using conductive tomography. They also measured the local heat transfer coefficients along the circumference of the tube. Unfortunately, no comparison has been made to tubes in a horizontal orientation.

- Mosyak and Hetsroni (1999) studied the occurrence of dry-out at the top of the tube for horizontal and $5^{\circ}$ upward air-water flow during intermittent flow. They showed that the dry-out has a strong influence on the heat transfer and that it does not occur for inclined upward tubes.

- Ghajar and Kim (2005) presented experimental results for horizontal and slightly inclined flows (up to $7^{\circ}$ ). They found that the heat transfer coefficients increased when the inclination angle increased (Fig. 16). For slug and bubbly-slug flows, they found that an inclination angle of $5^{\circ}$ was an optimum inclination angle. For other flow regimes, the highest tested inclination angle $\left(7^{\circ}\right)$ led to the highest heat transfer coefficient.

They proposed the inclination factor $I$ to take into account the effect of the gravity on the heat transfer coefficient:

$$
I=1+\frac{g D\left(\rho_{l}-\rho_{g}\right) \sin \beta}{\rho_{l} U_{s l}^{2}}
$$

With a total of 408 experimental data points obtained with air-water flow, they proposed the following correlation for the two-phase heat transfer coefficient $h_{t p}$ :

$$
h_{t p}=h_{l 0} F_{p}\left(1+0.7\left(\frac{x}{1-x}\right)^{0.08}\left(\frac{1-F_{p}}{F_{p}}\right)^{0.06}\left(\frac{P r_{g}}{P r_{l}}\right)^{0.03}\left(\frac{\mu_{l}}{\mu_{g}}\right)^{0.14}(I)^{0.65}\right)
$$


$h$ and $\operatorname{Pr}$ denote the heat transfer coefficient and the Prandtl number respectively. $h_{l 0}$ is the leading coefficient and comes from the Sieder and Tate (1936) correlation. $F_{p}$ is the flow pattern factor, which is defined as:

$$
F_{p}=(1-\varepsilon)+\varepsilon F_{S}
$$

and $F_{\mathrm{s}}$ being the shape factor, defined as:

$$
F_{s}=\frac{2}{\pi} \tan ^{-1}\left(\sqrt{\frac{\rho_{g}\left(U_{g}-U_{l}\right)^{2}}{g D\left(\rho_{l}-\rho_{g}\right) \cos \beta}}\right)
$$

$U_{g}$ and $U_{l}$ are liquid and vapour velocities respectively. $\varepsilon$ is calculated with the correlation of Chisholm (1973). The range of the parameters used is given in Table 1, as well as the results of the predictions when compared with measurements.

- Recently, Ghajar and Tang (2010) have published a review article on heat transfer correlations for liquid-gas two-phase flow in horizontal and upward inclined and upward vertical tubes. They compared their flow pattern maps with those proposed by Barnea (1987) and found a good agreement for all inclination angles. They proposed a new form of correlation for the heat transfer coefficient and used both their experimental results and those available in the literature to determine the parameters of the correlation. They obtained:

$$
h_{t p}=h_{l 0} F_{p}\left(1+0.55\left(\frac{x}{1-x}\right)^{0.1}\left(\frac{1-F_{p}}{F_{p}}\right)^{0.4}\left(\frac{P r_{g}}{P r_{l}}\right)^{0.25}\left(\frac{\mu_{l}}{\mu_{g}}\right)^{0.25}\left(I^{*}\right)^{0.25}\right)
$$

where $I^{*}$ is a modified inclination factor parameter:

$$
I^{*}=1+E o|\sin \beta|
$$

and $E o$ is the Eötvös number, defined as:

$$
E o=\frac{\left(\rho_{l-} \rho_{g}\right) g D^{2}}{\sigma}
$$

The modified inclination factor implies that the heat transfer is increased when the inclination angle increases, however, this correlation is limited to low inclination angles $\left(<7^{\circ}\right)$ and thus the equation is not able to predict an optimum inclination angle if it would exist for a higher inclination angle.

So far, no study have dealt with the variation of the heat transfer coefficient for the whole range of inclination angles. Thus, this gap needs to be filled in order to get a better understanding of heat transfer for two-phase flows in inclined tubes.

\subsection{Conclusion and perspectives}

This review of the studies of the effect of the inclination angle on the properties of two-phase flows shows that this kind of flow is far from being perfectly understood and predictable. Correlations and models still need to be improved and validated for a large range of fluids and flow conditions. 
So far, most of the experimental studies have led to global measurements, in the form of heat transfer coefficients and the pressure drops, in order to develop correlations. However, as the inclination effect is the result of the balance between capillary, gravitational and shear forces, the correlations are not able to represent the actual flow properties for a wide range of experimental conditions. The complexity of the different phenomena that lead two-phase flows in inclined tubes induces the necessity of developing complex mechanistic models. However, in order to validate these models, new original experimental facilities have to be developed in order to measure the fundamental properties of the flow in the tube (i.e. the liquid-vapour distribution properties), and not only the resulting flow properties (i.e. the pressure drops and heat transfer coefficients).

Moreover, most of the studies have been conducted with air-water flow, which has specific properties of high surface tension for the water and low density for the air. Extrapolating this kind of study to the case of condensing flow is thus questionable and more specific work has to be performed with two-phase saturated refrigerant flow for a better understanding of the effect of the properties of the fluids on the flow patterns, pressure drops and heat transfer coefficients.

\section{Condensation in inclined tubes}

Several literature reviews have been published about condensation (Cavallini et al., 2003; Liebenberg and Meyer, 2008; Dalkilic and Wongwises, 2009) but references to condensation in inclined tubes are very rare. According to the intensive literature review of condensation inside smooth and enhanced tubes of Dalkilic and Wongwises (2009), it seems as if most of the experimental studies in non-horizontal positions have been conducted inside vertical tubes. Condensation in inclined tubes has only been studied for reflux condensation in thermosyphons or reflux condensers (Fiedler and Auracher, 2004). Thus so far, review articles have never really focused on condensation in inclined tubes. The present article aims to fill this gap. The first part of this section is dedicated to condensation in vertical tubes, before focusing especially on condensation in inclined tubes.

\subsection{Vertical tubes}

\subsubsection{Modelling of condensing flow in vertical tubes}

The prediction of the pressure drops and heat transfer coefficients during condensation in vertical tubes has been the object of several articles available in the literature. The studies focus especially on annular two-phase flow, as it is the most common flow in vertical tubes. The classical Nusselt theory assumed a quiescent vapour along an isothermal vertical plate and no interfacial shear stress at the surface of the liquid film. These assumptions are not valid in forced convective condensation and several types of models have been developed.

For laminar film condensation, the Nusselt theory can be reviewed by taking into account the interfacial shear stress in the equation. For example, Seban and Hodgson (1982) proposed a numerical 
model to predict the liquid film thickness in a laminar film condensation of upward or downward steam. However, these models are limited to low liquid velocities.

Another type of model is based on the numerical solution of the hydrodynamic equations by the discretisation of the flow. Chen and Ke (1993) proposed a numerical model where three regions are taken into account: the inner region (liquid film near the wall), the outer region (vapour core in the centre of the tube) and the interfacial region. For each region, they used different models (turbulence model for the vapour flow, laminar or turbulent model for the liquid film, damping eddy diffusivity model for the interface, etc.). They showed that their model predicted the trends well of the experimental data, but improvements are still necessary for low and high vapour qualities and that the model was not suitable for mist and slug flows.

Panday (2003) developed the same type of model, without neglecting the inertia and convection terms in the equations and by using the mixing length proposed by Pletcher (1974) for the turbulent viscosity model. Panday solved the equations with an explicit finite difference scheme with a nonregular mesh. The model also predicts the heat transfer coefficients. He showed that for high velocities, the orientation of the tube had no influence on the flow properties in the case of turbulent condensation. Note that this kind of model was extended to study the condensation of vapour in the presence of a noncondensable gas (Groff et al., 2007).

The last type of model for annular flow is the three-fluid model. In this model the liquid film, the gas core and the droplets entrained from the liquid film into the gas core and deposited from the gas core onto the liquid surface are modelled. Mass, momentum and energy balance equations are written for each fluid stream. Stevanovic et al. (2008) used the three-fluid model to predict the pressure drops for downward condensing steam flow. They showed that this kind of model is strongly dependent on the correlation used to calculate the interfacial friction factor and they provided a comparison with different correlations used in the literature. The paper proposed a new correlation that predicts, among others, the experimental results of Kim and No (2000).

\subsubsection{Heat transfer coefficient correlation}

Several authors have given some correlations in order to predict the heat transfer coefficient in vertical flows. Gogonin (2004) published a review article on the heat transfer coefficients in condensation inside vertical tubes, especially for downward flows. The paper summarises the different correlations available in the literature and the different experimental studies with water and with other hydrocarbons. Dalkilic et al. (2009a) also presented different correlations developed for annular flows, which can be used for condensation in vertical tubes. According to Moser et al. (1998), the different correlations can be classified into three different types: the correlations based on the shear-stress (where the thermal resistance is supposed to be mainly located in the laminar sublayer of the liquid-film), on the boundary layer (where the thermal resistance is calculated taking into account the entire liquid film) 
and on a two-phase multiplier (where the flow is supposed to be similar to a single-phase flow with a correction factor).

Several authors studied the heat transfer during condensation considering annular flow regimes only. At high mass fluxes, the orientation of the tube does not influence the heat transfer and thus the different models can be used whatever the inclination angle (Kosky and Staub, 1971). For example, Shah (1979) proposed a unique correlation based on a two-phase multiplier for condensation in horizontal, inclined and vertical tubes:

$$
h_{t p}=h_{l 0}\left[(1-x)^{0.8}+\frac{3.8 x^{0.76}(1-x)^{0.04}}{\operatorname{Pr}^{0.38}}\right]
$$

This correlation was tested for various fluids, including water, refrigerant and alcohols and for a wide range of mass fluxes and heat fluxes. The prediction agreed quite well with experimental data. However, Kim and No (2000) conducted an experimental study of heat transfer coefficients and pressure drops during the condensation of steam in a $46 \mathrm{~mm}$ inside diameter vertical tube (downward flow). They concluded that the correlation of Shah did not show a good agreement with the data for such big tubes. They proposed a new model to calculate the heat transfer coefficients for these conditions.

For downward flow, Soliman et al. (1968) gave a correlation based on annular flow and Chen et al. (1987) proposed another one that accounts for the effect of interfacial shear and waves.

Other approaches can be possible: Moser et al. (1998) developed a model based on that of Akers et al. (1958), known as the "equivalent Reynolds number". The annular condensing flow must provide the same heat transfer than a liquid single-phase flow, defined by an equivalent Reynolds number. Moser et al. improved the model of Akers through to the heat-momentum analogy. They proposed a convenient reduced form of their model:

$$
N u=\frac{0.0994^{C_{1}} \operatorname{Re}_{l}^{C_{2}} \operatorname{Re}_{e q}^{1+0.875 C_{1}} \operatorname{Pr}_{l}^{0.815}}{\left(1.58 \ln R e_{e q}-3.28\right)\left(2.58 \ln R e_{e q}+13.7 P r_{l}^{2 / 3}-19.1\right)}
$$

with $C_{1}=0.126 \mathrm{Pr}_{l}^{-0.448}$ and $C_{2}=-0.113 P r_{l}^{-0563}$ for $R e_{e q}>112 . \mathrm{Nu}$ is the Nusselt number and $R e_{e q}$ is the equivalent Reynolds number and is defined as $R e_{e q}=\phi_{l 0}^{8 / 7} R e_{l 0}$ where $\phi_{l 0}$ is the two-phase multiplier defined by Friedel (1979).

They tested their new model with different kinds of refrigerants, for tube diameters ranging from $3.14 \mathrm{~mm}$ to $20 \mathrm{~mm}$ and for mass fluxes ranging from 100 to $862 \mathrm{~kg} / \mathrm{m}^{2} \mathrm{~s}$. The experimental database had 1197 points and they obtained a mean absolute deviation of $13.6 \%$.

So far, no correlations or models have been accepted by the research community and the validity of the correlations and models still have to be checked each time new experimental results are published. For example, Dalkilic et al. (2009a) compared their experimental results with 12 correlations available in the literature. Experiments were obtained with R134a condensing downward in an $8.1 \mathrm{~mm}$ inner diameter tube for mass fluxes ranging from 260 to $515 \mathrm{~kg} / \mathrm{m}^{2} \mathrm{~s}$. They noted that the correlations of Dobson and Chato (1998), Cavallini and Zecchin (1974) and Fujii (1995) gave better results than others 
for their experimental conditions. These correlations were developed for a horizontal orientation, but it seems as if the properties of annular flows are independent of tube orientation. The authors also presented a new correlation that best predicts their experimental results. However, in a following article, Dalkilic et al. (2009b) showed that these correlations were not valid for condensation at low mass fluxes. At these conditions, they advised using the modified Nusselt theory, presented by Carey (1992).

\subsubsection{Pressure drop correlation}

The modified Nusselt theory model allows the calculation of the pressure drops by considering the vapour core flowing in a round tube. Besides this theory, few studies are available about pressure drop for condensation in vertical tubes. Experimental data obtained for these conditions are often compared with pressure drop correlations for gas-liquid flow. However, such data are very rare and it is difficult to get a good overview of the validity of the correlations. For example, Kim and No (2000) compared their experimental results with the predictions of the modified Nusselt theory (Carey, 1992). They found that the model underpredicted the pressure drop by about $25 \%$.

Dalkilic et al. (2010) compared 13 two-phase pressure drop correlations with their experimental results obtained with condensing R134a in a vertical tube (downward flow) at a high mass flux. They found that the model of Cavallini et al. (2001) and the model of Chen et al. (2001) predicted the experimental pressure well. Both correlations were developed for a horizontal orientation. However, the comparison of experimental data with pressure drop correlations requires the calculation of the gravitational and the momentum pressure drops. In a previous paper, Dalkilic et al. (2008) showed that the choice of the void fraction model has a strong effect on the two-phase friction factor.

\subsubsection{Conclusion}

The most complete studies on condensation of downward flow of R134a in vertical tubes have certainly been conducted by Dalkilic and co-workers. The diameter of the tube is $8.1 \mathrm{~mm}$ and they performed tests with mass fluxes up to $600 \mathrm{~kg} / \mathrm{m}^{2} \mathrm{~s}$. They compared a database of pressure drops and heat transfer coefficients with different correlations available in the literature and conducted a study about the impact of the void fraction model on these correlations.

They showed that for high mass fluxes $\left(\mathrm{G}>260 \mathrm{~kg} / \mathrm{m}^{2} \mathrm{~s}\right)$, the annular flow regime is independent of the tube orientation. Thus, correlations developed for condensation in horizontal tubes can be used for vertical tubes. They verified this for heat transfer correlations (Dalkilic et al., 2009a), for pressure drops (Dalkilic et al., 2010) and even for flow pattern transitions (Dalkilic and Wongwises, 2010). They also showed that the void fraction model has a strong influence on the results of the other models. New experimental studies should focus particularly on the determination of the void fraction because of the importance of the gravitational pressure drops for two-phase flow in vertical tubes. It is shown in the next section that the knowledge of the void fraction in inclined tubes is also of major importance. In conclusion, more experimental studies are required for fully understanding condensing flow in vertical 
tubes with low mass fluxes, especially for upward flows, for which the experimental studies are almost non-existent.

\subsection{Inclined tubes}

Condensing flow can be separated into two types of flows, the gravity-led flow and the convective flow, depending on whether the fluid motion is due to the gravitational forces or an external device (pump, compressors, etc.). The present section deals with both types of flows.

\subsubsection{Gravity-led systems}

Condensation in inclined tubes occurs, among others, in thermosyphons or in reflux condensers. In these systems, vapour is flowing upwards and liquid flows downwards. This configuration leads to specific behaviour of the system, as the phenomenon of flooding. It occurs when some part of the condensate is carried upwards because of the shear stress between liquid and vapour. The maximum vapour velocity is called the flooding vapour velocity. Numerous articles deal with reflux condensation and some of them are interested in the inclination effect on the heat transfer coefficients. For example, Wang and Ma (1991) proposed a semi-empirical correlation for reflux condensation heat transfer in inclined thermosyphons:

$$
\frac{N u}{N u_{n}}=\left(\frac{2 L}{D}\right)^{\frac{\cos \beta}{4}}(0.54+0.00568 \beta)
$$

where $N u_{n}$ is the average Nusselt number according to the classical Nusselt film theory for condensation in a vertical tube. According to this correlation, there is a specific inclination angle that leads to the highest heat transfer coefficient. This study has been followed by many other researchers to try to predict the thermosyphon optimum inclination. Amongs others, Fiedler et al. (2002) studied the effect of the inclination angle on flooding and heat transfer in a thermosyphon with a $7 \mathrm{~mm}$ inside diameter tube filled with R134a (Fig. 17). They found an optimum angle in terms of heat transfer close to $40^{\circ}$. For this angle, the heat transfer is almost twice as high as for the vertical position $\left(90^{\circ}\right)$. They proposed a modified Wang and Ma correlation that predicts their results well. More recently, Noie et al. (2007) have studied the effect of the inclination angle and the filling ratio on the heat transfer coefficient. They found that the optimum angle was between $30^{\circ}$ and $45^{\circ}$. They also found that the condensation heat transfer coefficient increased when the filling ratio increased.

Besides the correlations, authors have also tried to develop mechanistic models. Fiedler and Auracher (2004) proposed a model of condensation inside a thermosyphon. They considered a falling condensing film on the upper part of the tube and a stratified flow for the lower part. The authors found a good agreement with the experimental data in terms of heat transfer coefficient (deviation less than $15 \%)$.

So far, no correlation or model has been able to represent all the experimental data available in the literature and authors have compared their models with very limited ranges of experimental 
conditions. It highlights the fact that condensation in gravity-led systems is far from being perfectly understood. However, some of the results can be used for the study of convective condensation: reflux condensation deals with counter-current flows at low mass fluxes and thus with low liquid-vapour interfacial shear stresses whereas in convective condensation a co-current liquid-vapour flow exists with potentially very high interfacial shear. The notion of reflux condensation and the notion of flooding limit can be applied for condensation in upward tubes with very low mass fluxes. Furthermore, the studies of condensation in thermosyphons can be used for convective condensation dominated by gravitational forces, thus for low mass fluxes. During these conditions, experimental studies show that there exists an optimum inclination angle for which the heat transfer coefficient is a maximum. However, further experiments are necessary to predict the optimum inclination angle depending on the operating conditions.

\subsubsection{Convective condensation}

The first studies about convective condensation in inclined tubes are more than 50 years old. Chato (1960) conducted a theoretical and an experimental study of laminar condensation into horizontal and inclined tubes. Experiments were done using R113 with a test section slope up to $10^{\circ}$ (downward concurrent flow). The test section was a copper tube with $14.5 \mathrm{~mm}$ inner diameter and during his experiments, condensate flow was very low $\left(10^{-7}\right.$ to $3.10^{-6} \mathrm{~m}^{3} / \mathrm{s}$ at the outlet of the test section) and the vapour Reynolds number was up to 35 000. Under these conditions, Chato concluded that increasing the inclination increased the heat transfer coefficient because of the decrease in the liquid flow thickness. The inclination angle also had an effect on the waves and ripples at the liquid-vapour interface. For low inclination angles, the waves due to the liquid-vapour shear stress disappeared but for larger inclination angles, deeper waves due to gravitational forces appeared randomly. In his thesis, Chato (1960) also cited the study of Tepe and Mueller (1947) about condensation of benzene in an inclined tube. According to him, with an $18.8 \mathrm{~mm}$ inner diameter tube and an inclination angle of $15^{\circ}$, Tepe and Mueller measured heat transfer coefficients $50 \%$ higher than the Nusselt theory.

It has also been shown that tilting the tube affects the flow pattern transitions: Nitheanandan and Soliman (1993) performed an experimental study of the effect of the tube inclination on the flow regime boundaries during condensation of water. They used a $13.8 \mathrm{~mm}$ inner diameter copper tube. The range of tube inclination was from $10^{\circ}$ downwards to $10^{\circ}$ upwards. The range of mass fluxes was $20-280$ $\mathrm{kg} / \mathrm{m}^{2} \mathrm{~s}$. During these conditions, they found that the influence of the angle of inclination on the annular flow regime boundary was almost insignificant. However, even a small inclination angle has a strong influence on wavy and slug flow regime transitions: wavy flow is more prominent in downward inclinations and slug flow is more prominent in upward inclinations. No significant changes were found between inclination angles of $5^{\circ}$ and $10^{\circ}$. They concluded that the flow pattern map during condensation was equivalent to an adiabatic gas-liquid flow pattern map with the addition of a slight inclination angle, due to the increase of the liquid height along the condenser. In a following article (Nitheanandan and 
Soliman, 1994), they proposed a mechanistic model to predict the transition between stratified and nonstratified flow in their experiments. The model is an extension of the model of Taitel and Dukler (1976) and accounts for the condensation process in the momentum balance. The authors studied the influence of the inclination angle and of the condensing heat flux on the stratified-non-stratified flow regime transition (Fig. 18). It appears that for low inclination angles, an increase in the heat transfer is the equivalent of an increase in the inclination angle (in upward direction). It can be noted that for a larger inclination angle in downward flow, the condensing effect is negligible. The model was successfully compared with the experimental data published in their previous article (Nitheanandan and Soliman, 1993) .

Some authors have conducted studies about convective condensation for the whole range of inclination angles. For example, Wang et al. (1998) conducted an experimental study of the flow pattern transition during condensation of R11 in a $6 \mathrm{~mm}$ inside diameter. The mass fluxes ranged from 9 to $123.2 \mathrm{~kg} / \mathrm{m}^{2} \mathrm{~s}$. The authors described the different flow patterns present depending on the inclination angle (Fig. 19) and proposed some correlations for the transition characteristics in terms of liquid ( $\left.W e_{l}\right)$ and vapour $\left(W e_{v}\right)$ Weber numbers:

$$
W e_{v}=C W e_{l}^{n}
$$

$C$ and $n$ are functions of the tube inclination and the flow pattern transition, as summarised in Table 2 .

Würfel et al. (2003) presented an experimental study of two-phase flow inside an inclined tube (20 mm inner diameter, angle of inclination: $0^{\circ}, 11^{\circ}, 30^{\circ}, 45^{\circ}, 90^{\circ}$ ). They measured two-phase friction coefficients, local thicknesses, void fractions and entrainment for a gas-vapour flow (air-n-heptane) and heat transfer coefficients during condensation of $n$-heptane in downward flows. They concluded that the inclination angle has no effect on the pressure drop. However, the heat transfer coefficients increased with an increase in the inclination and they developed a correlation taking into account the inclination angle. The effect of the inclination can be written as:

$$
\frac{N u}{N u_{0}}=(1+\sin \beta)^{0.214}
$$

where $N u_{0}$ is the Nusselt number for the horizontal orientation. This correlation correlates with their experimental results with a mean square error of $12 \%$. According to this correlation, an inclination angle of $35^{\circ}$ increases the heat transfer coefficient with $10 \%$ compared with the horizontal position.

The fact that an optimum inclination angle exists was also noticed by Akhavan-Behabadi et al. (2007), who studied experimentally, the effect of the inclination angle of a microfin tube for condensing flow of R134a. The inside diameter of the tube was $8.92 \mathrm{~mm}$ and three mass fluxes were tested $(54,81$ and $107 \mathrm{~kg} / \mathrm{m}^{2} \mathrm{~s}$ ). They recorded the heat transfer coefficient for vapour qualities ranging from 0.2 to 0.8 for different inclination angles (from $-90^{\circ}$ to $90^{\circ}$ with steps of $30^{\circ}$ ). They found that the heat transfer coefficients were higher for downward flow than for upward flows. An optimum also exists in terms of 
inclination angle: during their experiments, they found that the inclination that leads to the highest heat transfer coefficient was $30^{\circ}$. Based on their experimental data, they produced the following correlation:

$$
N u=1.09 R e_{l}^{0.45} F_{\beta}^{0.3} \sqrt{\frac{P r_{l}}{X_{t t}}}
$$

with $X_{\mathrm{tt}}$ being the Martinelli parameter and $F_{\beta}$ an inclination factor, defined as:

$$
F_{\beta}=\frac{1+(1-x)^{0.2} \cos \left(\beta-10^{\circ}\right)}{x^{0.4}}
$$

From this correlation, it is possible to plot the ratio between the Nusselt number in an inclined position to a horizontal position (Fig. 20). There is a difference of about $20 \%$ and $15 \%$ between the heat transfer coefficients in horizontal flow and in vertical upward and downward flows respectively.

As the experimental studies about condensation in inclined tubes are very rare, no general trends can be drawn so far. A better understanding of the different phenomena leading convective condensation in inclined tubes can be obtained through the development of new mechanistic models. However, Narain et al. (1997) highlighted the difficulty of the modelling of inclined condensing flow and particularly at the onset of condensation. The authors showed that this point has a mathematical discontinuity in the model and proposed an asymptotic form of the governing equations in this case. They also compared different interfacial shear models for horizontal and vertical configurations.

More recently, Wang and Du (2000) conducted a theoretical and experimental study on laminar film-wise condensation of water vapour in a small inclined tube (downward flow). They developed an analytical model to predict the shape of the liquid-vapour interface for a stratified flow pattern. They conducted experiments with different tube diameters $(1.94 \mathrm{~mm}, 2.80 \mathrm{~mm}, 3.95 \mathrm{~mm}$ and $4.98 \mathrm{~mm})$, different inclination angles $\left(0^{\circ}, 17^{\circ}, 34^{\circ}\right.$ and $\left.45^{\circ}\right)$ and with a low range of mass fluxes $\left(10-100 \mathrm{~kg} / \mathrm{m}^{2} \mathrm{~s}\right)$. For small tubes $(1.98$ and $2.80 \mathrm{~mm})$, the Nusselt number increased slightly when the tube inclination increased. For larger tubes ( 3.95 and $4.98 \mathrm{~mm}$ ), the effect of inclination angle was stronger: for low liquid quality ( $1-x$ lower than $0.4-0.6)$, the Nusselt number decreased with increasing inclination. For larger liquid qualities, the Nusselt number increased with an increase in inclination, even if the horizontal orientation led to the highest Nusselt number. This study highlights the complexity of the balance between the gravitational, capillary and shear forces depending on the size of the tube, the vapour quality and the mass flux. The authors explained their results as the effect of the gravity on the thickness of the liquid film. They compared their analytical model, in terms of heat transfer coefficients, with the experimental results. The deviations were within a range of -28 to $+20 \%$. However, their model is only valid for small tubes, with regard to the capillary length of the fluid, for which the shape of the liquid-vapour interface is mainly driven by capillary forces.

As a conclusion, we can note that the studies about convective condensation in inclined tubes are very rare. This literature review does not make it possible to determine the general trends of the inclination effect on condensing flow. The reason is that some authors noticed an improvement of the heat transfer when the inclination angle increases, whereas some others observed the opposite with an 
optimum inclination angle. This can be explained by the discrepancy between the experimental conditions of the different authors. We have seen in the previous section that the inclination effect depends strongly on the flow pattern map, and thus on the experimental conditions. Thus, more experimental studies about condensation inside inclined tubes are necessary to achieve a good understanding of this kind of flow and to develop predictive tools.

\section{Conclusions}

This review considered the flow modelling of inclined two-phase flow, in terms of flow pattern maps, void fractions, heat transfer coefficients and pressure drops. The knowledge of these different parameters is of major importance in the design of heat exchangers. However, despite numerous studies, no generalised method for the prediction of two-phase flow properties has been widely accepted in the literature.

An important parameter in two-phase flows is the void fraction and its prediction is a major issue in two-phase flow applications. The lack of experimental studies with void fraction measurements does not allow a good overview of the effect of the inclination angle. Studies with inclined air-water flows definitely showed a strong effect but no satisfactory correlation that really accounts for the gravitational effect has been developed yet. No study on void fractions has been conducted during inclined convective condensation.

It has also been showed that the inclination angle affects the flow pattern maps. However, the inclination effect on the flow patterns has been studied for the whole range of inclination angles only for air-water flows. For convective condensation, flow patterns have been studied only for horizontal or vertical downward flows.

The literature showed that the inclination angle can have a significant effect on the heat transfer coefficients. It seems that for specific configurations, an optimum inclination angle can be found, but once more, no general correlation has been developed. Note that particular attention has to be given when comparing two-component (liquid-gas) flows and one-component (liquid-vapour) flows as the phenomena during heat transfer are different. More studies about heat transfer during inclined convective condensation have to be conducted to get a good understanding of the main trends of the gravitational effects on the flow.

The study of pressure drops during inclined two-phase flows is complicated by the need of separating the momentum, frictional and static pressure drops. The momentum and static pressure drops are strongly dependent on the void fraction, which is quite difficult to measure accurately. Few studies deal with the pressure drop in inclined tubes and none of them have been conducted during convective condensation in inclined tubes.

This literature survey emphasises the fact that two-phase flows in inclined tubes are far from being fully understood and highlights the lack of predictive tools in this field. More studies of the process 
of condensation in inclined tubes are also required, as the models and correlations have been developed for condensation in horizontal tubes only.

In light of the complexity of the balance between the different phenomena that occur in convective condensation in inclined tubes, new experimental studies should be performed in two parts: firstly, general studies are required to determine the main trends of the inclination effect on the flow patterns, heat transfer coefficients and pressure drops for a large range of fluids and experimental conditions. This would allow a good overview of the different behaviours encountered, which mostly depend on the main forces influencing the flow (capillary, gravitational, shear stress, etc.). The second part would be to focus on each of these behaviours separately with specific experimental set-ups and specific models. The experimental set-up should be designed to measure not only the output of the models (heat transfer coefficients and pressure drops), but also the fundamental properties of the flow. This includes the distribution of the liquid and the vapour inside the tube (through the shape of the liquid-vapour interface, the void fraction, the liquid film thickness, the entrainment, the wetted perimeter, the slipping ratio, etc., in order to validate all steps of the mechanistic models. This approach would require that more sophisticated experimental set-ups be developed. 


\section{References}

Abdul-Majeed, G.H., Al-Mashat, A.M., 2000. A mechanistic model for vertical and inclined two-phase slug flow. J. Pet. Sci. Eng. 27, 59-67.

Akers, W.W., Deans, H.A., Crosser, O.K., 1958. Condensing heat transfer within horizontal tubes. Chem. Eng. Prog. Symp. Ser. 59, 171-176.

Akhavan-Behabadi, M.A., Kumar, R., Mohseni, S.G., 2007. Condensation heat transfer of R134a inside a microfin tube with different tube inclinations. Int. J. Heat Mass Transfer $50,4864-4871$.

Barnea, D., 1987. A unified model for predicting flow-pattern transitions for the whole range of pipe inclinations. Int. J. Multiphase Flow 13, 1-12.

Beggs, D.H., Brill, J.P., 1973. A study of two-phase flow in inclined pipes. J. Pet. Technol. 25.

Brauner, N., Moalem Maron, D., 1992. Analysis of stratified/non-stratified transitional boundaries in inclined gas-liquid flows. Int. J. Multiphase Flow 18, 541-557.

Brauner, N., Moalem Maron, D., Rovinsky, J., 1998. A two-fluid model for stratified flows with curved interfaces. Int. J. Multiphase Flow 24, 975-1004.

Brauner, N., Rovinsky, J., Moalem Maron, D., 1996. Determination of the interface curvature in stratified two-phase systems by energy considerations. Int. J. Multiphase Flow 22, 1167-1185.

Carey, V.P., 1992. Liquid-vapor phase-change phenomena. Hemisphere, New York.

Cavallini, A., Censi, G., Del Col, D., Doretti, L., Longo, G.A., Rossetto, L., 2001. Experimental investigation on condensation heat transfer and pressure drop of new HFC refrigerants (R134a, R125, R32, R410A, R236ea) in a horizontal smooth tube. Int. J. Refrig. 24, 7387.

Cavallini, A., Censi, G., Del Col, D., Doretti, L., Longo, G.A., Rossetto, L., Zilio, C., 2003. Condensation inside and outside smooth and enhanced tubes - a review of recent research. Int. J. Refrig. 26, 373-392.

Cavallini, A., Del Col, D., Doretti, L., Longo, G.A., Rossetto, L., 2000. Heat transfer and pressure drop during condensation of refrigerants inside horizontal enhanced tubes. Int. J. Refrig. 23, 4-25.

Cavallini, A., Zecchin, R., 1974. A dimensionless correlation for heat transfer in forced convection condensation, in: Proceedings of the Fifth International Heat Transfer Conference. pp. 309-313.

Chato, J.C., 1960. Laminar condensation inside horizontal and inclined tubes. 
Chen, I.Y., Yang, K.S., Chang, Y.J., Wang, C.C., 2001. Two-phase pressure drop of air-water and R-410A in small horizontal tubes. Int. J. Multiphase Flow 27, 1293-1299.

Chen, S.L., Gerner, F.M., Tien, C.L., 1987. General film condensation correlations. Exp. Heat Transfer 1, 93-107.

Chen, S.L., Ke, M.T., 1993. Forced convective film condensation inside vertical tubes. Int. J. Multiphase Flow 19, 1045-1060.

Cheng, L., Ribatski, G., Thome, J.R., 2008. Two-phase flow patterns and flow-pattern maps: fundamentals and applications. Appl. Mech. Rev. 61, 050802-28.

Chisholm, D., 1973. Pressure gradients due to friction during the flow of evaporating two-phase mixtures in smooth tubes and channels. Int. J. Heat Mass Transfer 16, 347-358.

Cho, J.M., Kim, Y.J., Kim, M.S., 2010. Experimental studies on the evaporative heat transfer and pressure drop of $\mathrm{CO} 2$ and $\mathrm{CO} 2$ /propane mixtures flowing upward in smooth and micro-fin tubes with outer diameter of $5 \mathrm{~mm}$ for an inclination angle of $45^{\circ}$. Int. J. Refrig. In Press, Corrected Proof.

Coddington, P., Macian, R., 2002. A study of the performance of void fraction correlations used in the context of drift-flux two-phase flow models. Nucl. Eng. Des. 215, 199-216.

Crawford, T.J., Weinberger, C.B., Weisman, J., 1985. Two-phase flow patterns and void fractions in downward flow. Part I: steady-state flow patterns. Int. J. Multiphase Flow $11,761-782$.

Dalkilic, A.S., Agra, O., Teke, I., Wongwises, S., 2010. Comparison of frictional pressure drop models during annular flow condensation of R600a in a horizontal tube at low mass flux and of R134a in a vertical tube at high mass flux. Int. J. Heat Mass Transfer 53, 20522064.

Dalkilic, A.S., Laohalertdecha, S., Wongwises, S., 2008. Effect of void fraction models on the two-phase friction factor of R134a during condensation in vertical downward flow in a smooth tube. Int. Commun. Heat Mass Transfer 35, 921-927.

Dalkilic, A.S., Laohalertdecha, S., Wongwises, S., 2009. Experimental investigation of heat transfer coefficient of R134a during condensation in vertical downward flow at high mass flux in a smooth tube. Int. Commun. Heat Mass Transfer 36, 1036-1043.

Dalkilic, A.S., Wongwises, S., 2009. Intensive literature review of condensation inside smooth and enhanced tubes. Int. J. Heat Mass Transfer 52, 3409-3426.

Dalkilic, A.S., Wongwises, S., 2010. Validation of void fraction models and correlations using a flow pattern transition mechanism model in relation to the identification of annular vertical downflow in-tube condensation of R134a. Int. Commun. Heat Mass Transfer 
$37,827-834$.

Dalkilic, A.S., Yildiz, S., Wongwises, S., 2009. Experimental investigation of convective heat transfer coefficient during downward laminar flow condensation of R134a in a vertical smooth tube. Int. J. Heat Mass Transfer 52, 142-150.

Diener, R., Friedel, L., 1998. Reproductive accuracy of selected void fraction correlations for horizontal and vertical upflow. Forsch. Ingenieurwes. 64, 87-97.

Dobson, M.K., Chato, J.C., 1998. Condensation in smooth horizontal tubes. J. Heat Transfer $120,193$.

El Hajal, J., Thome, J.R., Cavallini, A., 2003. Condensation in horizontal tubes. Part 1: twophase flow pattern map. Int. J. Heat Mass Transfer 46, 3349-3363.

Fair, J.R., 1960. What you need to design thermosiphon reboilers. Pet. Refin. 39, 105-123.

Fiedler, S., Auracher, H., 2004. Experimental and theoretical investigation of reflux condensation in an inclined small diameter tube. Int. J. Heat Mass Transfer 47, 40314043.

Fiedler, S., Auracher, H., Winkelmann, D., 2002. Effect of inclination on flooding and heat transfer during reflux condensation in a small diameter tube. Int. Commun. Heat Mass Transfer 29, 289-302.

Friedel, L., 1979. Improved friction pressure drop correlations for horizontal and vertical twophase pipe flow, in: European two-phase flow group meeting, Paper E.

Fujii, T., 1995. Enhancement to condensing heat transfer - new developments, in: Fuel and Energy Abstracts. p. 360.

Fukano, T., Ousaka, A., 1989. Prediction of the circumferential distribution of film thickness in horizontal and near-horizontal gas-liquid annular flows. Int. J. Multiphase Flow 15, 403-419.

Geraci, G., Azzopardi, B.J., Van Maanen, H.R.E., 2007a. Effect of inclination on circumferential film thickness variation in annular gas/liquid flow. Chem. Eng. Sci. 62, 3032-3042.

Geraci, G., Azzopardi, B.J., Van Maanen, H.R.E., 2007b. Inclination effects on circumferential film flow distribution in annular gas/liquid flows. AIChE J. 53, 1144-1150.

Ghajar, A.J., Kim, J., 2005. A non-boiling two-phase flow heat transfer correlation for different flow patterns and pipe inclination angles, in: Proceedings of the 2005 ASME Summer Heat Transfer Conference. pp. 17-22.

Ghajar, A.J., Tang, C.C., 2010. Importance of non-boiling two-phase flow heat transfer in pipes for industrial applications. Heat Transfer Eng. 31, 711-732. 
Gogonin, I.I., 2004. Heat transfer in condensation of vapor moving inside vertical tubes. J. Eng. Phys. Thermophys. 77, 454-470.

Gomez, L.E., Shoham, O., Taitel, Y., 2000. Prediction of slug liquid holdup: horizontal to upward vertical flow. Int. J. Multiphase Flow 26, 517-521.

Grönnerud, R., 1972. Investigation of liquid hold-up, flow-resistance and heat transfer in circulation type evaporators. Part IV: Two-phase flow resistance in boiling refrigerants. Bull. De l'Inst. Du Froid, Annexe 1.

Greskovich, E.J., Cooper, W.T., 1975. Correlation and prediction of gas-liquid holdups in inclined upflows. AIChE J. 21, 1189-1192.

Groff, M.K., Ormiston, S.J., Soliman, H.M., 2007. Numerical solution of film condensation from turbulent flow of vapor-gas mixtures in vertical tubes. Int. J. Heat Mass Transfer $50,3899-3912$.

Grolman, E., Fortuin, J.M.H., 1997a. Liquid hold-up, pressure gradient, and flow patterns in inclined gas-liquid pipe flow. Exp. Therm. Fluid Sci. 15, 174-182.

Grolman, E., Fortuin, J.M.H., 1997b. Gas-liquid flow in slightly inclined pipes. Chem. Eng. Sci. 52, 4461-4471.

Hart, J., Hamersma, P.J., Fortuin, J.M.H., 1989. Correlations predicting frictional pressure drop and liquid holdup during horizontal gas-liquid pipe flow with a small liquid holdup. Int. J. Multiphase Flow 15, 947-964.

Hetsroni, G., Mewes, D., Enke, C., Gurevich, M., Mosyak, A., Rozenblit, R., 2003. Heat transfer to two-phase flow in inclined tubes. Int. J. Multiphase Flow 29, 173-194.

Hewitt, G.F., Roberts, D.N., 1969. Studies of two-phase flow patterns by simultaneous x-ray and flash photography.

Hewitt, G.F., 1994. Heat Transfer 1994. Taylor \& Francis.

Kattan, N., Thome, J.R., Favrat, D., 1998. Flow boiling in horizontal tubes. Part 1: Development of a diabatic two-phase flow pattern map. J. Heat Transfer 120, 140-147.

Kim, S.J., No, H.C., 2000. Turbulent film condensation of high pressure steam in a vertical tube. Int. J. Heat Mass Transfer 43, 4031-4042.

Kokal, S.L., Stanislav, J.F., 1989. An experimental study of two-phase flow in slightly inclined pipes II. Liquid holdup and pressure drop. Chem. Eng. Sci. 44, 681-693.

Kosky, P.G., Staub, F.W., 1971. Local condensing heat transfer coefficients in the annular flow regime. AIChE J. 17, 1037-1043.

Laurinat, J.E., Hanratty, T.J., Jepson, W.P., 1985. Film thickness distribution for gas-liquid annular flow in a horizontal pipe, in: Two-phase annular and dispersed flows: selected 
papers presented at the International Symposium on Two-Phase Annular and Dispersed Flows, University of Pisa, Italy, 24-29 June 1984. p. 179.

Liebenberg, L., Meyer, J.P., 2008. A review of flow pattern-based predictive correlations during refrigerant condensation in horizontally smooth and enhanced tubes. Heat Transfer Eng. 29, 3-19.

Lioumbas, J.S., Mouza, A.A., Paras, S.V., Karabelas, A.J., 2007. Liquid layer characteristics in stratified gas-liquid downflow: a study of transition to wavy flow. Heat Transfer Eng. $28,625-632$.

Lioumbas, J.S., Paras, S.V., Karabelas, A.J., 2005. Co-current stratified gas-liquid downflow Influence of the liquid flow field on interfacial structure. Int. J. Multiphase Flow 31, 869-896.

Müller-Steinhagen, H., Heck, K., 1986. A simple friction pressure drop correlation for twophase flow in pipes. Chem. Eng. Process. 20, 297-308.

Magrini, K., Sarica, C., Al-Sarkhi, A., Zhang, H.Q., 2010. Liquid Entrainment in Annular Gas/Liquid Flow in Inclined Pipes, in: SPE Annual Technical Conference and Exhibition.

Mandhane, J.M., Gregory, G.A., Aziz, K., 1974. A flow pattern map for gas-liquid flow in horizontal pipes. Int. J. Multiphase Flow 1, 537-553.

Mickley, H.S., Ross, R.C., Squyers, A.L., Stewart, W.E., 1953. Heat, mass, and momentum transfer for flow over a flat plate with blowing or suction. NACA-TN-3208, Massachusetts Inst. of Tech.

Miyara, A., 2008. Condensation of hydrocarbons - A review. Int. J. Refrig. 31, 621-632.

Moreno Quibén, J., Thome, J.R., 2007a. Flow pattern based two-phase frictional pressure drop model for horizontal tubes. Part II: New phenomenological model. Int. J. Heat Fluid Flow 28, 1060-1072.

Moreno Quibén, J., Thome, J.R., 2007b. Flow pattern based two-phase frictional pressure drop model for horizontal tubes. Part I: Diabatic and adiabatic experimental study. Int. J. Heat Fluid Flow 28, 1049-1059.

Moser, K.W., Webb, R.L., Na, B., 1998. A new equivalent Reynolds number model for condensation in smooth tubes. J. Heat Transfer 120, 410.

Mosyak, A., Hetsroni, G., 1999. Analysis of dryout in horizontal and inclined tubes. Int. J. Multiphase Flow 25, 1521-1543.

Mukherjee, H., Brill, J.P., 1983. Liquid holdup correlations for inclined two-phase flow. J. Pet. Technol. 35, 1003-1008. 
Mukherjee, H., Brill, J.P., 1985a. Empirical equations to predict flow patterns in two-phase inclined flow. Int. J. Multiphase Flow 11, 299-315.

Mukherjee, H., Brill, J.P., 1985b. Pressure drop correlations for inclined two-phase flow. J. Energy Resour. Technol. 107, 549-554.

Narain, A., Yu, G., Liu, Q., 1997. Interfacial shear models and their required asymptotic form for annular/stratified film condensation flows in inclined channels and vertical pipes. Int. J. Heat Mass Transfer 40, 3559-3575.

Nguyen, V.T., Spedding, P.L., 1977. Holdup in two-phase, gas-liquid flow - II: Experimental results. Chem. Eng. Sci. 32, 1015-1021.

Nitheanandan, T., Soliman, H.M., 1993. Influence of tube inclination on the flow regime boundaries of condensing steam. Can. J. Chem. Eng. 71, 35-41.

Nitheanandan, T., Soliman, H.M., 1994. Analysis of the stratified/nonstratified transitional boundary in horizontal and slightly inclined condensing flows. Can. J. Chem. Eng. 72, 26-34.

Noie, S.H., Emami, M.R.S., Khoshnoodi, M., 2007. Effect of inclination angle and filling ratio on thermal performance of a two-phase closed thermosyphon under normal operating conditions. Heat Transfer Eng. 28, 365.

Ould Didi, M.B., Kattan, N., Thome, J.R., 2002. Prediction of two-phase pressure gradients of refrigerants in horizontal tubes. Int. J. Refrig. 25, 935-947.

Pan, L., Hanratty, T.J., 2002a. Correlation of entrainment for annular flow in horizontal pipes. Int. J. Multiphase Flow 28, 385-408.

Pan, L., Hanratty, T.J., 2002b. Correlation of entrainment for annular flow in vertical pipes. Int. J. Multiphase Flow 28, 363-384.

Panday, P.K., 2003. Two-dimensional turbulent film condensation of vapours flowing inside a vertical tube and between parallel plates: a numerical approach. Int. J. Refrig. 26, 492503.

Pletcher, R.H., 1974. Prediction of transpired turbulent boundary layers. J. Heat Transfer 96, 89.

Revellin, R., Haberschill, P., 2009. Prediction of frictional pressure drop during flow boiling of refrigerants in horizontal tubes: Comparison to an experimental database. Int. J. Refrig. 32, 487-497.

Rouhani, S.Z., Axelsson, E., 1970. Calculation of void volume fraction in the subcooled and quality boiling regions. Int. J. Heat Mass Transfer 13, 383-393.

Sawant, P., Ishii, M., Mori, M., 2008. Droplet entrainment correlation in vertical upward co- 
current annular two-phase flow. Nucl. Eng. Des. 238, 1342-1352.

Seban, R.A., Hodgson, J.A., 1982. Laminar film condensation in a tube with upward vapor flow. Int. J. Heat Mass Transfer 25, 1291-1300.

Shah, M.M., 1979. A general correlation for heat transfer during film condensation inside pipes. Int. J. Heat Mass Transfer 22, 547-556.

Sieder, E.N., Tate, G.E., 1936. Heat transfer and pressure drop of liquids in tubes. Ind. Eng. Chem. 28, 1429-1435.

Soliman, M., Schuster, J.R., Berenson, P.J., 1968. A general heat transfer correlation for annular flow condensation. J. Heat Transfer 90, 267-276.

Spedding, P.L., 1997. Holdup Prediction in Vertical Upwards to Downwards Flow. Dev. Chem. Eng. Mineral Process. 5, 43-60.

Spedding, P.L., Chen, J.J.J., Nguyen, V.T., 1982. Pressure drop in two phase gas-liquid flow in inclined pipes. Int. J. Multiphase Flow 8, 407-431.

Spedding, P.L., Nguyen, V.T., 1980. Regime maps for air water two phase flow. Chem. Eng. Sci. 35, 779-793.

Spedding, P.L., Watterson, J.K., Raghunathan, S.R., Ferguson, M.E.G., 1998. Two-phase cocurrent flow in inclined pipe. Int. J. Heat Mass Transfer 41, 4205-4228.

Spindler, K., Hahne, E., 1999. An experimental study of the void fraction distribution in adiabatic water-air two-phase flows in an inclined tube. Int. J. Therm. Sci. 38, 305-314.

Steiner, D., 1993. Heat transfer to boiling saturated liquids. VDI-Wārmeatlas (VDI Heat Atlas), Verein Deutscher Ingenieure, VDI-Gesellschaft Verfahrenstechnik und Chemieingenieurwesen (GCV), Düsseldorf, Chapter Hbb.

Stevanovic, V.D., Stanojevic, M., Radic, D., Jovanovic, M., 2008. Three-fluid model predictions of pressure changes in condensing vertical tubes. Int. J. Heat Mass Transfer $51,3736-3744$.

Suliman, R., Liebenberg, L., Meyer, J.P., 2009. Improved flow pattern map for accurate prediction of the heat transfer coefficients during condensation of R-134a in smooth horizontal tubes and within the low-mass flux range. Int. J. Heat Mass Transfer 52, $5701-5711$.

Taitel, Y., Dukler, A.E., 1976. A model for predicting flow regime transitions in horizontal and near horizontal gas-liquid flow. AIChE J. 22, 47-55.

Tepe, J.B., Mueller, A.C., 1947. Condensation and subcooling inside an inclined tube. Chem. Eng. Progress 43, 267-278.

Thome, J.R., 2006. Engineering Data Book III. Huntsville, AL: Wolverine Tube, Inc. 
Thome, J.R., El Hajal, J., Cavallini, A., 2003. Condensation in horizontal tubes. Part 2: new heat transfer model based on flow regimes. Int. J. Heat Mass Transfer 46, 3365-3387.

Ullmann, A., Zamir, M., Gat, S., Brauner, N., 2003. Multi-holdups in co-current stratified flow in inclined tubes. Int. J. Multiphase Flow 29, 1565-1581.

Ursenbacher, T., Wojtan, L., Thome, J.R., 2004. Interfacial measurements in stratified types of flow. Part I: New optical measurement technique and dry angle measurements. Int. J. Multiphase Flow 30, 107-124.

Würfel, R., Kreutzer, T., Fratzscher, W., 2003. Turbulence transfer processes in adiabatic and condensing film flow in an inclined tube. Chem. Eng. Technol. 26, 439-448.

Wang, B.-X., Du, X.-Z., 2000. Study on laminar film-wise condensation for vapor flow in an inclined small/mini-diameter tube. Int. J. Heat Mass Transfer 43, 1859-1868.

Wang, J.C.Y., Ma, Y., 1991. Condensation heat transfer inside vertical and inclined thermosyphons. J. Heat Transfer 113, 777-780.

Wang, W.C., Ma, X.H., Wei, Z.D., Yu, P., 1998. Two-phase flow patterns and transition characteristics for in-tube condensation with different surface inclinations. Int. J. Heat Mass Transfer 41, 4341-4349.

Weisman, J., Duncan, D., Gibson, J., Crawford, T., 1979. Effects of fluid properties and pipe diameter on two-phase flow patterns in horizontal lines. Int. J. Multiphase Flow 5, 437462.

Weisman, J., Kang, S.Y., 1981. Flow pattern transitions in vertical and upwardly inclined lines. Int. J. Multiphase Flow 7, 271-291.

Woldesemayat, M.A., Ghajar, A.J., 2007. Comparison of void fraction correlations for different flow patterns in horizontal and upward inclined pipes. Int. J. Multiphase Flow 33, 347370.

Xu, J.-yu, Wu, Y.-xiang, Shi, Z.-hong, Lao, L.-yun, Li, D.-hui, 2007. Studies on two-phase cocurrent air/non-Newtonian shear-thinning fluid flows in inclined smooth pipes. Int. J. Multiphase Flow 33, 948-969.

Yan, Y.-Y., Lin, T.-F., 1999. Condensation heat transfer and pressure drop of refrigerant R134a in a small pipe. Int. J. Heat Mass Transfer 42, 697-708.

Zhang, H.Q., Wang, Q., Sarica, C., Brill, J.P., 2003. A unified mechanistic model for slug liquid holdup and transition between slug and dispersed bubble flows. Int. J. Multiphase Flow 29, 97-107. 


\section{List of figure captions}

Fig. 1. Effect of the inclination angle on a flow pattern map (Ghajar and Kim, 2005).

Fig. 2. Inclination correction angle as a function of inclination angle, adapted from Beggs and Brill (1973).

Fig. 3. Geometry considered by Taitel and Dukler for stratified flow, adapted from Taitel and Dukler (1976).

Fig. 4. Pumping action of the disturbance waves, adapted from Fukano and Ousaka (1989).

Fig. 5. Pressure drop as a function of the inclination angle, adapted from Spedding et al. (1982) (air-water flow in a $4.55 \mathrm{~mm}$ inner diameter pipe ; $U_{\mathrm{sl}}=0.018 \mathrm{~m} / \mathrm{s}$ ).

Fig. 6. Effect of the inclination angle on the heat transfer coefficient (BS: Bubbly-Slug, ABS: Annular-Bubbly-Slug), adapted from Ghajar and Kim (2005).

Fig. 7. Effect of inclination angle on reflux condensation heat transfer for a $7 \mathrm{~mm}$ tube and R134a (Fiedler et al., 2002).

Fig. 8. Effect of inclination and heat flux on the stratified/non-stratified flow, adapted from Nitheanandan and Soliman (1994).

Fig. 9. Schematic drawings of condensation flow patterns for orientations, adapted from Wang et al. (1998).

Fig. 10. Effect of the inclination angle on the heat transfer for R134a condensing in a microfin 8.92 mm inside diameter tube at mass fluxes from 54 to $107 \mathrm{~kg} / \mathrm{m}^{2} \mathrm{~s}$ (Akhavan-Behabadi et al., 2007). 
Table 1

Range of experimental parameters and statistic indicators (Ghajar and Kim, 2005).

\begin{tabular}{|c|c|c|c|c|c|c|c|c|c|}
\hline \multirow[b]{2}{*}{$R e_{\mathrm{sl}}$} & \multicolumn{5}{|c|}{ Range of the parameter } & \multirow{2}{*}{$\begin{array}{c}\text { Mean } \\
\text { dev. } \\
{[\%]}\end{array}$} & \multirow{2}{*}{$\begin{array}{c}\text { Std. } \\
\text { Dev. } \\
{[\%]}\end{array}$} & \multirow{2}{*}{$\begin{array}{c}\text { Dev. } \\
\text { Range } \\
{[\%]}\end{array}$} & \multirow{2}{*}{$\begin{array}{l}\text { No. Of Data } \\
\text { within } \pm 20 \%\end{array}$} \\
\hline & $F_{\mathrm{p}}$ & $x$ & $P r_{\mathrm{g}} / \operatorname{Pr}_{1}$ & $\mu_{\mathrm{g}} / \mu_{1}$ & $I$ & & & & \\
\hline 835 & $0.198-$ & $7.92 \times 10^{-4}$ & 0.074 & 0.013 & 1 & & & -30.7 & \\
\hline to & to & to & to & to & to & -4.22 & 12.5 & To & 367 \\
\hline 25966 & 0.729 & 0.487 & 0.110 & 0.020 & 1.734 & & & 37 & \\
\hline
\end{tabular}

Table 2

Coefficients of the flow pattern transitions for R11 flowing in a $6 \mathrm{~mm}$ inner diameter tube (Wang et al., 1998).

\begin{tabular}{cccc}
\hline $\begin{array}{c}\text { Flow pattern } \\
\text { transition }\end{array}$ & Orientation & \multicolumn{2}{c}{$(\Theta=1-\sin \beta)$} \\
\hline Annular/stratified & Downward & $97.1 \Theta$ & $0.459 e^{0.183 \Theta}$ \\
& Upward & $187.2-247.9 \Theta+145.3 \Theta^{2}$ & $0.221+0.789 \Theta$ \\
Stratified/Half-slug & All & $-236.8+363.2 \Theta$ & $-0.3948 \Theta^{2}$ \\
& & $-0.405+2.056 \Theta$ & $4.294-5.584 \Theta+2.04 \Theta^{2}$ \\
Half-slug/slug & All & $-0.537 \Theta^{2}$ & \\
& & \multicolumn{2}{c}{$-0.822-2.153 \Theta+0.9 \Theta^{2}$} \\
\hline
\end{tabular}




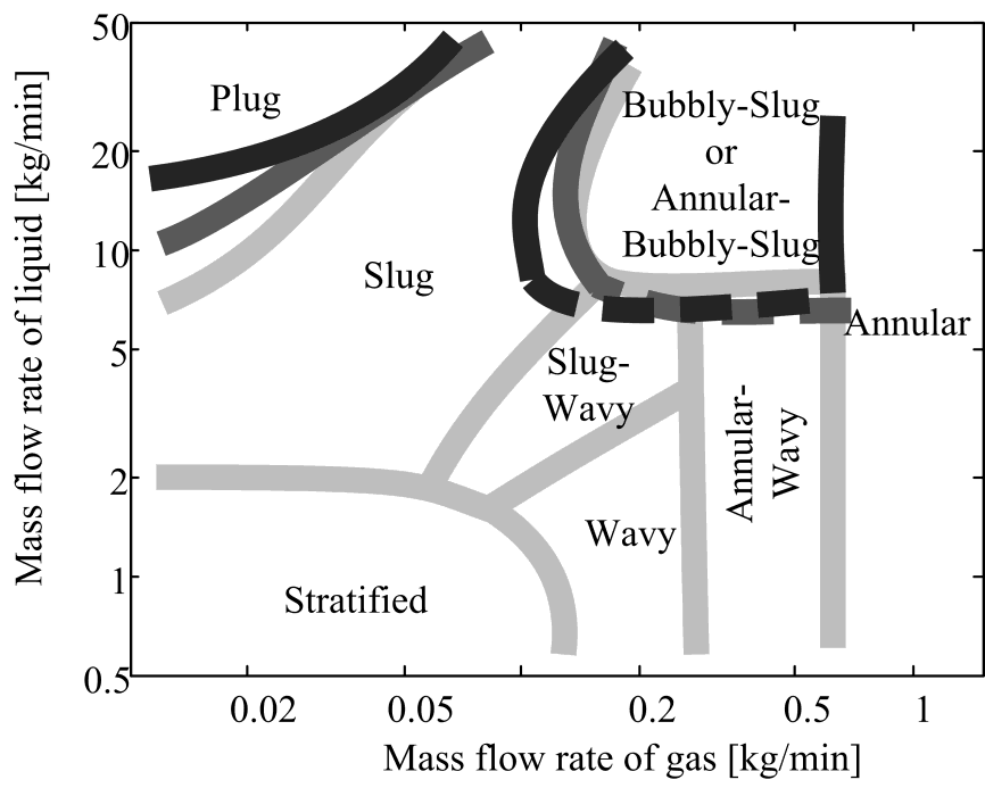

Flow pattern transition line

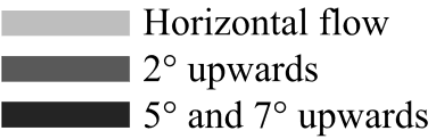

Fig. 11. Effect of the inclination angle on a flow pattern map (Ghajar and Kim, 2005). 


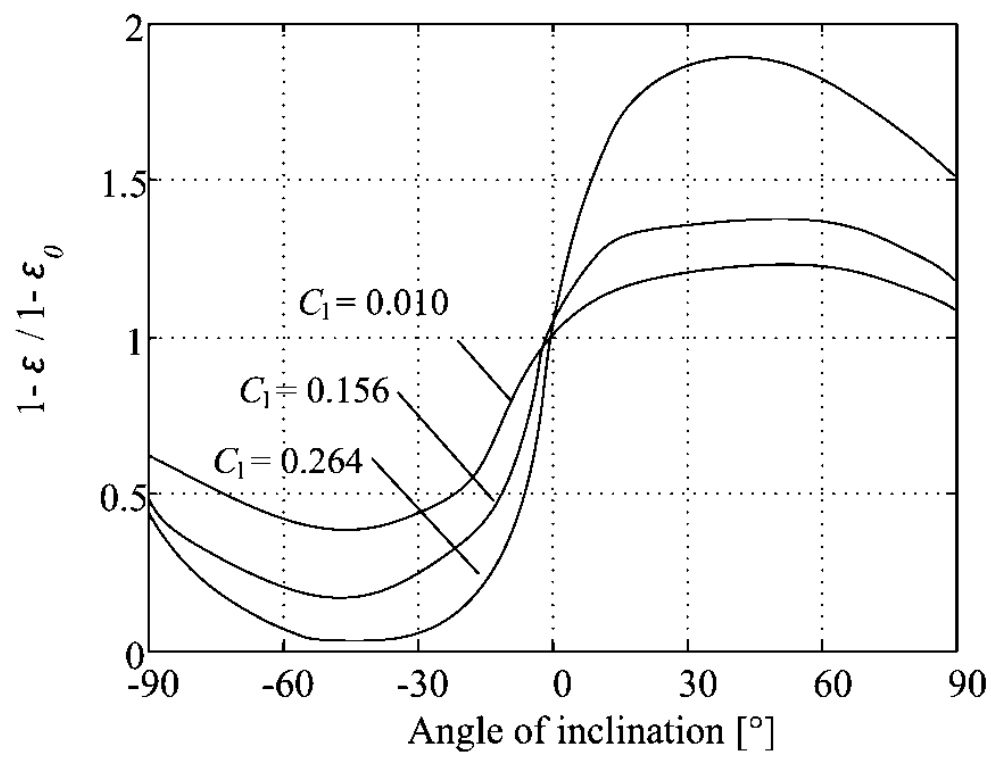

Fig. 12. Inclination correction angle as a function of inclination angle, adapted from Beggs and Brill (1973). 

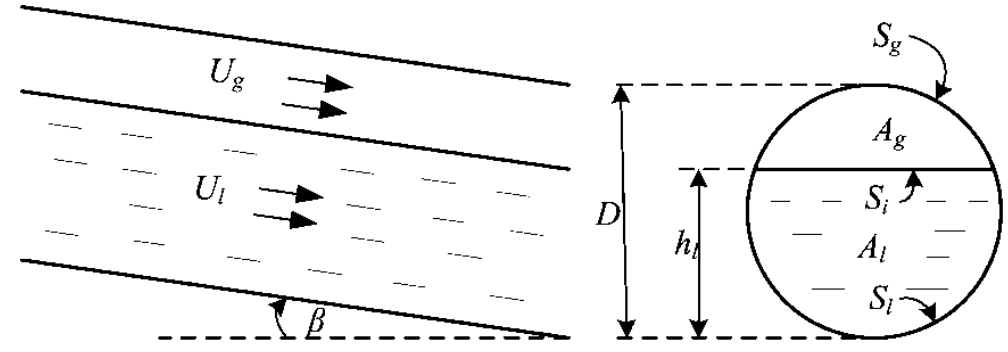

Fig. 13. Geometry considered by Taitel and Dukler for stratified flow, adapted from Taitel and Dukler (1976). 


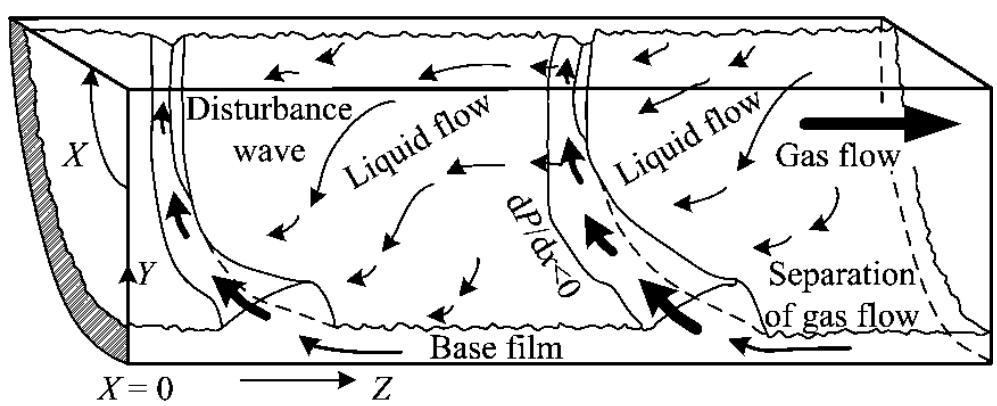

Fig. 14. Pumping action of the disturbance waves, adapted from Fukano and Ousaka (1989). 


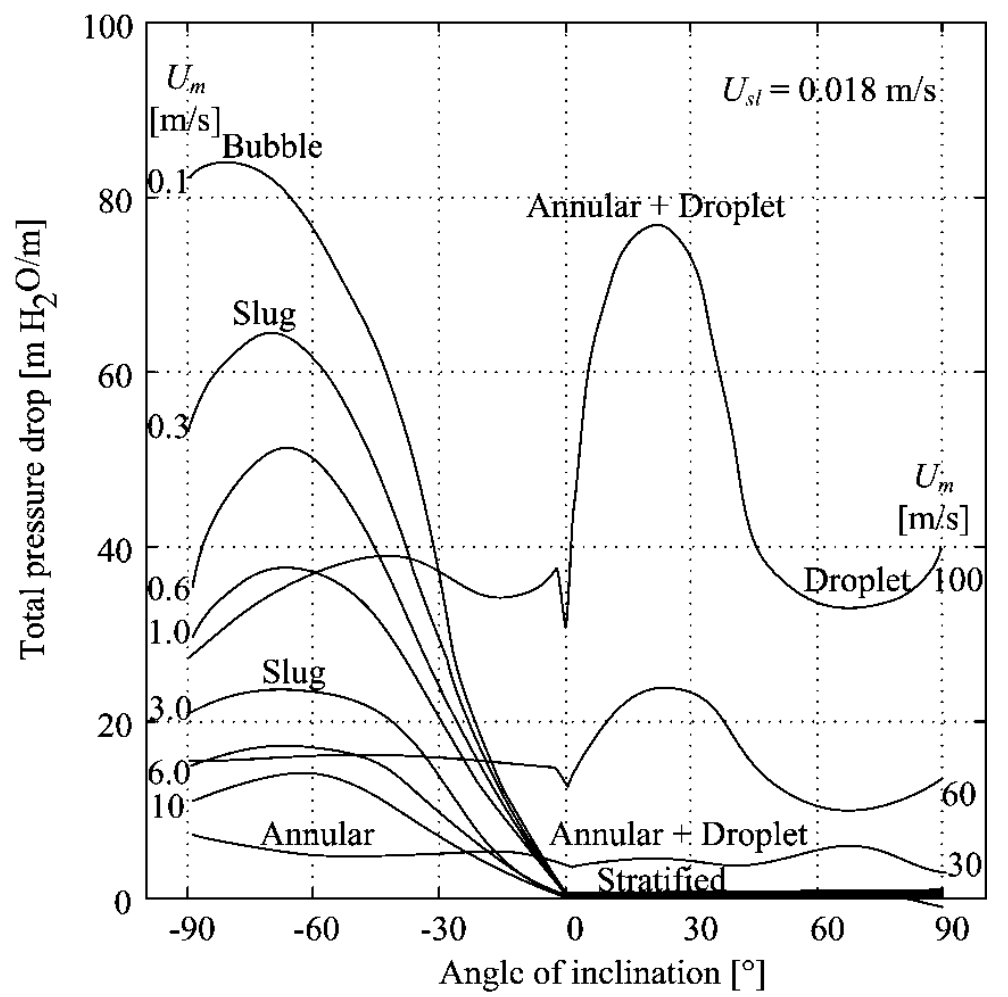

Fig. 15. Pressure drop as a function of the inclination angle, adapted from Spedding et al. (1982) (air-water flow in a $4.55 \mathrm{~mm}$ inner diameter pipe ; $U_{\mathrm{sl}}=0.018 \mathrm{~m} / \mathrm{s}$ ). 


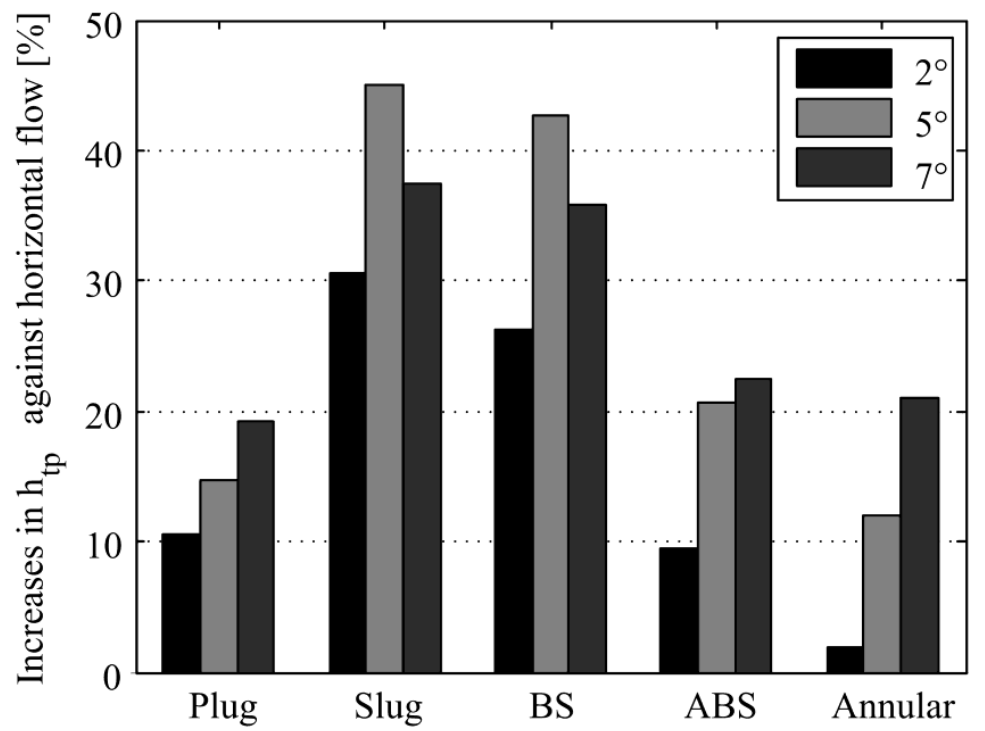

Fig. 16. Effect of the inclination angle on the heat transfer coefficient (BS: Bubbly-Slug, ABS: Annular-Bubbly-Slug), adapted from Ghajar and Kim (2005). 


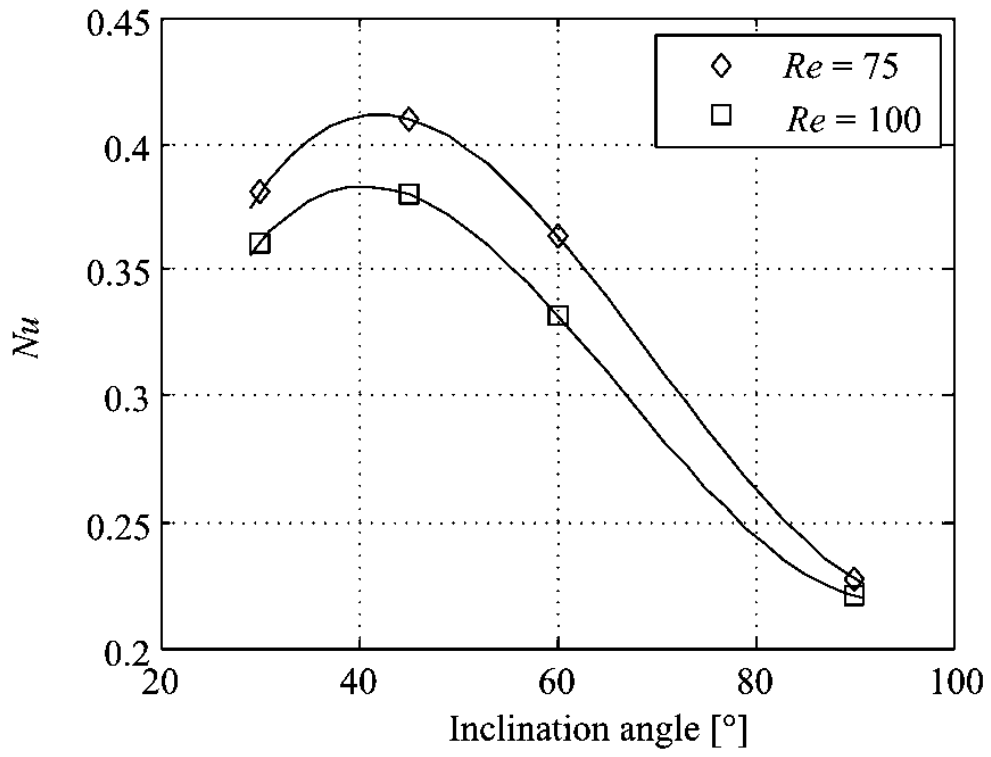

Fig. 17. Effect of inclination angle on reflux condensation heat transfer for a $7 \mathrm{~mm}$ tube and R134a (Fiedler et al., 2002). 


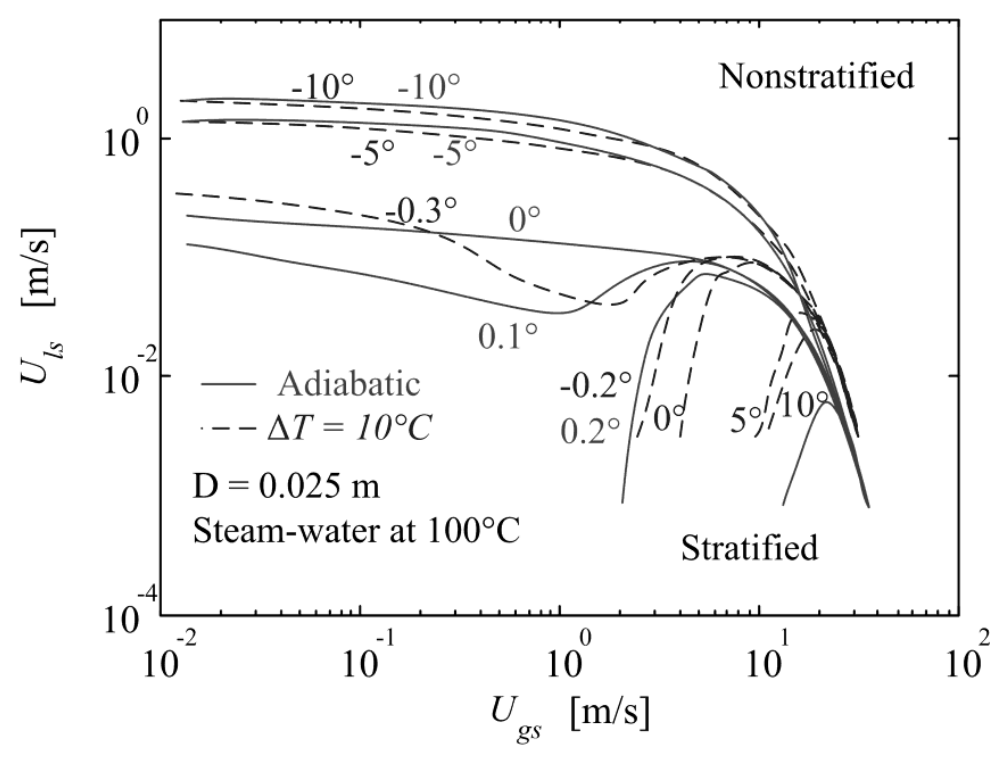

Fig. 18. Effect of inclination and heat flux on the stratified/non-stratified flow, adapted from Nitheanandan and Soliman (1994). 
(a) $\beta=-90^{\circ}$

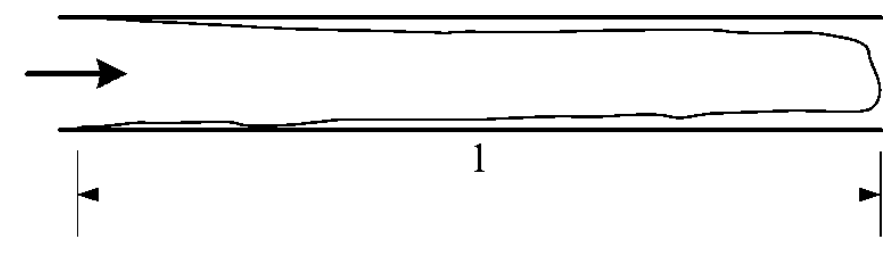

(b) $\beta=-45^{\circ}$

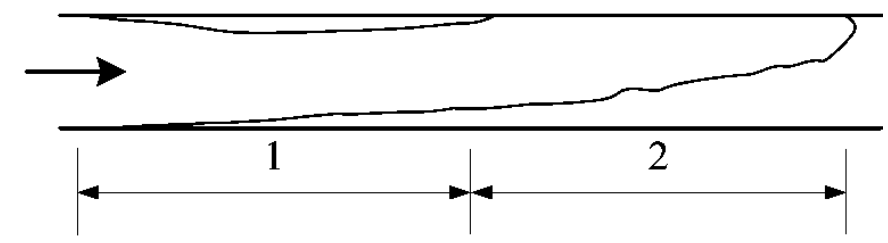

(c) $\beta=-30^{\circ}$

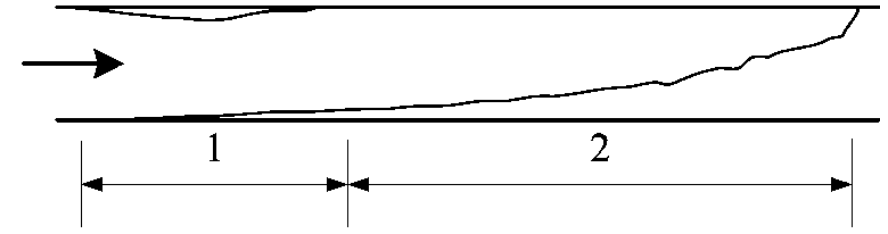

(d) $\beta=0^{\circ}$

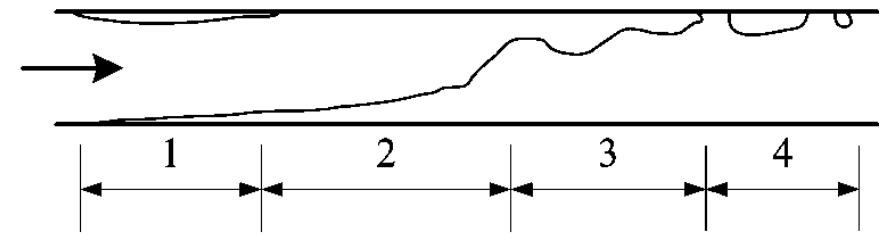

(e) $\beta=10^{\circ}$

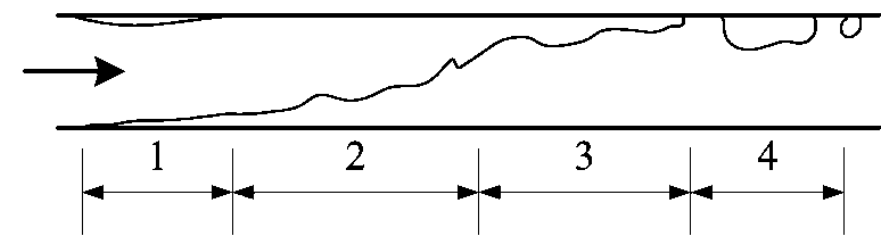

(f) $\beta=30^{\circ}$

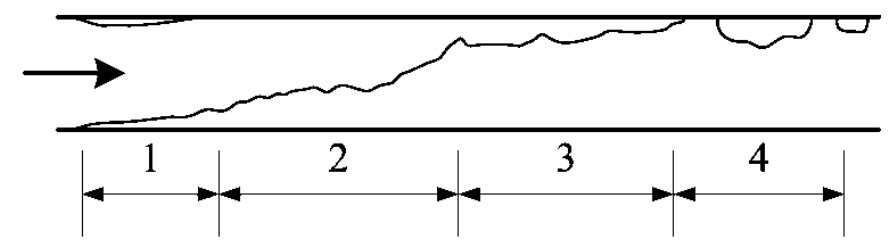

(g) $\beta=90^{\circ}$

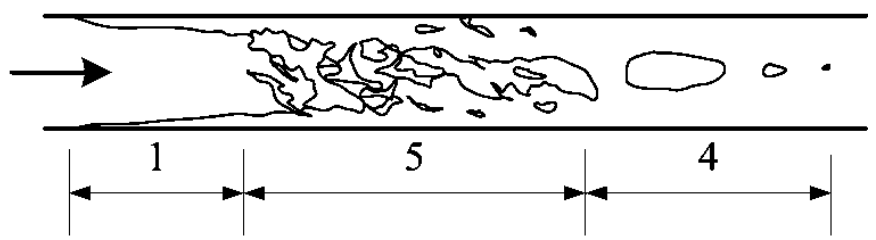

1 - Annular flow ; 2 - Stratified flow ; 3 - Half-Slug flow ;

4 - Slug flow ; 5 - Churn flow

Fig. 19. Schematic drawings of condensation flow patterns for orientations, adapted from Wang et al. (1998). 


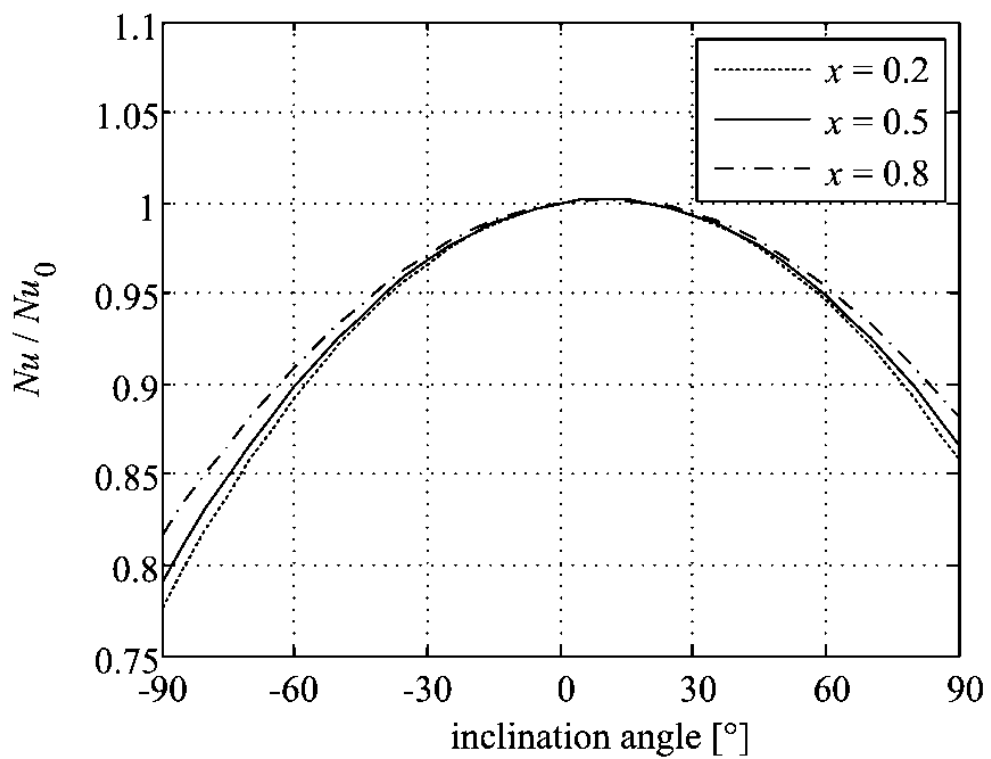

Fig. 20. Effect of the inclination angle on the heat transfer for R134a condensing in a microfin $8.92 \mathrm{~mm}$ inside diameter tube at mass fluxes from 54 to $107 \mathrm{~kg} / \mathrm{m}^{2} \mathrm{~s}$ (Akhavan-Behabadi et al., 2007). 